\title{
Effects of Histidine Protonation and Phosphorylation on Histidine-Containing Phosphocarrier Protein Structure, Dynamics, and Physicochemical Properties ${ }^{\dagger}$
}

\author{
Nadine Homeyer, ${ }^{\ddagger} \S$ Timm Essigke, ${ }^{\S, \|}$ G. Matthias Ullmann," and Heinrich Sticht*," \\ Abteilung für Bioinformatik, Institut für Biochemie, Friedrich-Alexander-Universität Erlangen-Nürnberg, Fahrstrasse 17, \\ 91054 Erlangen, Germany, and Structural Biology/Bioinformatics, Lehrstuhl Biopolymere, Universität Bayreuth, \\ Universitätsstrasse 30, 95447 Bayreuth, Germany
}

Received June 21, 2007; Revised Manuscript Received August 17, 2007

\begin{abstract}
Previous structural studies of the histidine-containing phosphocarrier protein (HPr) have shown that active site residue His 15 can adopt two distinct conformations which were termed OPEN and CLOSED. Using molecular dynamics simulations and protonation probability calculations, we were able to show that these two conformations correspond to different protonation forms of the histidine ring. The CLOSEDto-OPEN transition requires His 15 to adopt a conformation with higher energy, which is compensated by the favorable energetic consequences of protonation. Calculations of the conformational energy of His15 show that HPr exists mainly in the CLOSED form at $\mathrm{pH}$ 7. The very low apparent $\mathrm{p} K_{\mathrm{a}}$ value $(3.2-4.5)$ of the CLOSED conformation and the fact that the imidazole ring of residue 15 is primarily unprotonated at $\mathrm{N} \delta 1$ at neutral $\mathrm{pH}$ ensure that His 15 is ideally primed to be specifically phosphorylated at $\mathrm{N} \delta 1$. In contrast to unphosphorylated HPr, the phosphorylated form exhibits no conformational transitions, and the CLOSED state is stable even for the protonated imidazole ring due to favorable interactions between the phosphate group and the backbone of Ala16 and Arg17. These observations from MD simulations are confirmed by a simple four-microstate model which can explain both the $\mathrm{pH}$-dependent conformational change of unphosphorylated HPr and the conformational rigidity of phosphorylated HPr. Our study suggests that the predominant CLOSED conformation is relevant for HPr function in the phosphotransfer reaction, while the OPEN form of unphosphorylated HPr might be important for its additional regulatory function, in which an OPEN conformation of His15 is recognized by the transcriptional regulator CcpA.
\end{abstract}

The histidine-containing phosphocarrier protein $(\mathrm{HPr})^{1}$ is a small, phosphorylable compound, which is involved in the regulation of a number of processes associated with carbohydrate uptake and consumption in various bacterial species. It was discovered in 1964 by Kundig et al. as a component of the phosphoenolpyruvate:sugar phosphotransferase system (PTS) (1). Apart from its phosphocarrier function within the PTS phosphotransfer cascade, HPr can modulate the activity

This work was supported by grants from the Deutsche Forschungsgemeinschaft (SFB473, C10 to H.S. and UL 174/7-1 to G.M.U.). N.H. acknowledges a fellowship from the BioMedTec International Graduate School of Science (BIGSS), supported by the state of Bavaria.

* To whom correspondence should be addressed. Telephone: +49 9131/85 24614. Fax: +49-9131/85 22485. E-mail: h.sticht@biochem.unierlangen.de.

Friedrich-Alexander-Universität Erlangen-Nürnberg.

$\S$ These authors contributed equally to this work.

"Universität Bayreuth.

${ }^{1}$ Abbreviations: AMBER, Assisted Model Building with Energy Refinement; CcpA, carbon catabolite control protein A; EI, Enzyme I; EII, Enzyme II; HPr, histidine-containing phosphocarrier protein; HPrHis $15_{\mathrm{H} \epsilon}$, histidine-containing phosphocarrier protein with histidine at sequence position 15 protonated at the $\mathrm{N} \epsilon 2$ atom; HPr-His $15_{\mathrm{H} 2+}$, histidine-containing phosphocarrier protein with histidine at sequence position 15 protonated at both nitrogen atoms of the imidazole ring; HPr-His15P, histidine-containing phosphocarrier protein with phosphohistidine at position 15; MD, molecular dynamics; MEAD, Molecular Electrostatics with Atomic Detail; NMR, nuclear magnetic resonance; PDB, Protein Data Bank; PTS, phosphoenolpyruvate:sugar phosphotransferase system. of carbohydrate specific regulators, catabolic enzymes, permeases, and transcription factors (2).

The regulatory effects and functions of HPr are primarily based on its ability to be transiently phosphorylated. The protein contains two phosphorylation sites, His15 and Ser46. Regulatory phosphorylation of Ser46 takes place in Grampositive bacteria and is accomplished by an ATP-dependent kinase/phosphatase (3). This phosphorylation allows HPr to bind to the transcriptional regulator $\mathrm{CcpA}$ and to convert CcpA into its DNA-binding-competent conformation. Under conditions of low intracellular glucose concentrations, His 15 is phosphorylated to give HPr-His 15P, which has a catalytic function in the PTS. The PTS consists of a number of proteins and enzymes that sequentially transfer a phosphoryl group from phosphoenolpyruvate (PEP) to a sugar molecule which is concomitantly transported across the membrane into the bacterial cell (4). In the first step of the phosphotransfer cascade, a PEP-dependent protein kinase, enzyme I (EI), phosphorylates HPr at the imidazole $\mathrm{N} \delta 1$ of residue His 15 (5). Subsequently, the phosphoryl group is delivered to the imported sugar via the carbohydrate specific enzyme II (EII), which consists of three or four domains, EIIA, EIIB, and EIIC/D, present as either separate polypeptides or linked together in a multidomain protein. HPr-His15P transfers the phosphoryl group to the $\mathrm{N} \epsilon 2$ atom of a histidine residue of EIIA. This domain passes the phosphate moiety to EIIB, which then phosphorylates the carbohydrate transported by 
EIIC across the cell membrane $(6,7)$. As HPr-His15P can also phosphorylate and thereby activate non-PTS proteins, including catabolic enzymes and transcriptional regulators of genes encoding PTS substrates and enzymes for carbohydrate degradation (8), the phosphorylation state of HPr plays an important role in bacterial sugar metabolism.

Three-dimensional structures of HPr proteins from various bacterial species are known today. Among the HPr proteins that have been studied in detail by NMR spectroscopy and/ or X-ray crystallography are those from Escherichia coli (9, 10), Enterococcus faecalis (11-13), Bacillus subtilis (14, 15), Staphylococcus carnosus (16, 17), and Staphylococcus aureus (18). These proteins exhibit a very similar open-faced $\beta$-sandwich fold consisting of a four-stranded, antiparallel $\beta$-sheet which is flanked on one side by two long helices $(\alpha 1$ and $\alpha 3)$ and one short helix $(\alpha 2)$. The site for active phosphotransfer, which comprises His 15 and the highly conserved $\operatorname{Arg} 17$, is situated on top of the first helix $(\alpha 1)$ in a well-ordered loop (13).

Despite the common overall folding topology, the local geometry in the vicinity of the phosphorylation site His 15 differs among the known HPr structures. The observation of different relative orientations of the two main active center residues His 15 and Arg 17 in several novel three-dimensional structures of HPr led to the introduction of special terms for the description of the active site geometry. Depending on the spatial relation between the side chains of Arg17 and His 15, two main conformations of the active center (OPEN and CLOSED) were described $(9,11,19,20)$.

It has been proposed that the conformational flexibility of the active site might be important for His 15 in becoming phosphorylated (21), while other researchers speculated that the OPEN conformation is mainly favored at low $\mathrm{pH}$ values at which the ring of His 15 is positively charged $(13,18-$ 20 ). To study how the protonation and phosphorylation state of the active site residue His 15 affects the local and global features of the protein, we performed molecular dynamics (MD) simulations of six different HPr structures. Moreover, we conducted electrostatic calculations to analyze the protonation behavior of His15 and His15P in different structures. The results of these two complementary theoretical approaches allowed a comprehensive characterization of the conformational transitions in the active site of HPr.

\section{MATERIALS AND METHODS}

Protonation Probability Calculations. The protonation probability of all Arg, Asp, Glu, Lys, and His residues in HPr was calculated using a continuum electrostatic approach (22). For the unphosphorylated protein, structures were taken from PDB entries 2HPR (14), 1KKM (23), 1KA5 (18), 1FU0 (12), and 1PTF (11), including three examples of the CLOSED (2HPR, 1KKM, and 1KA5) and three examples of the OPEN (1PTF, 1FU0 chain A, and 1FU0 chain B) conformation. In contrast to MD simulations, where the choice of the starting structure is less critical because the structure can relax during the simulation, electrostatic calculations are particularly sensitive to structural inaccuracies. Therefore, special attention was paid to the selection of suitable structures, and high-resolution crystal structures were used for this type of analysis whenever available.

For analysis of the phosphorylated protein (HPr-His 15P), for which no crystal structure is available, seven models (given in Table 3) were randomly chosen from the 25 structures in the 1JEM ensemble of NMR structures. All crystal water atoms and ions were deleted from the PDB data sets. Commonly used model $\mathrm{p} K_{\mathrm{a}}$ values (22) and AMBER charges were used. Missing charges were computed by the previously described protocol (24). The model $\mathrm{p} K_{\mathrm{a}}$ for protonating the imidazole of His $15 \mathrm{P}$ was set to 7.0 according to the method of Gassner et al. (25).

The electrostatic potential was calculated using the Poisson-Boltzmann equation as implemented in $\operatorname{MEAD}(26,27)$. We used a dielectric constant of 4.0 for the protein and of 80.0 for the aqueous solution, and the ionic strength was set to $0.1 \mathrm{M}$. The electrostatic potential was calculated in two focusing steps using a grid of $81^{3}$ points, which had a grid spacing of 1.0 and $0.25 \AA$. Monte Carlo titration was performed as described elsewhere (22) to obtain protonation probability curves. To understand the origin of the differences in the protonation probability of His 15 in the OPEN and CLOSED conformation, the electrostatic energies were decomposed into Born, background, and interaction energies. The difference in Born energy $\left(\Delta G_{\text {Born }}\right)$ and background energy $\left(\Delta G_{\text {back }}\right)$ for a protonation reaction of a site can be directly obtained from the electrostatic calculations. However, the mean-field interaction energy $\left[\left\langle\bar{G}_{\text {inter }}\left(j_{\mathrm{k}}, \mathrm{pH}\right)\right\rangle\right]$ of protonation form $\mathrm{k}$ of site $j$ depends on the protonation of all other titratable sites at a given $\mathrm{pH}$. Using a scheme similar to the Tanford-Roxby approximation (28), the interaction energy can be estimated using the protonation probability $\left\langle x\left(l_{\mathrm{m}},-\right.\right.$ $\mathrm{pH})\rangle$ of each protonation form $\mathrm{m}$ of all the other sites $l$ at a given $\mathrm{pH}$, where $m$ represents the protonated (p) or deprotonated (d) form. However, instead of approximating the probability in a self-consistent iteration scheme, we use here the protonation probability obtained from the Monte Carlo titration to calculate the mean-field interaction energy. The mean interaction energy of site $j$ is given by

$$
\begin{array}{r}
\left\langle\bar{G}_{\text {inter }}\left(j_{\mathrm{k}}, \mathrm{pH}\right)\right\rangle=\sum_{l \neq j}^{N_{\text {site }}}\left[G_{\text {inter }}\left(j_{\mathrm{k}}, l_{\mathrm{p}}\right)\left\langle x\left(l_{\mathrm{p}}, \mathrm{pH}\right)\right\rangle+\right. \\
\left.G_{\text {inter }}\left(j_{\mathrm{k}}, l_{\mathrm{d}}\right)\left\langle x\left(l_{\mathrm{d}}, \mathrm{pH}\right)\right\rangle\right]
\end{array}
$$

where $N_{\text {site }}$ represents the number of titratable sites. Since the mean interaction energy is $\mathrm{pH}$-dependent, the decomposition of the apparent $\mathrm{p} K_{\mathrm{a}}$ value into the Born, background, model compound, and mean-field interaction energy is only exact for the $\mathrm{pH}$ equal to the apparent $\mathrm{p} K$ value.

HPr Templates for MD Simulations. Six HPr structures from B. subtilis and En. faecalis were used for the MD analysis. Structures taken from PDB data sets 1PTF (11), $1 F U 0$ chain A (12), and 1FU0 chain B (12) represented the OPEN conformation. Models derived from PDB entries 1JEM (15), 2HID (15), and 1QFR (13) represented the CLOSED conformation. In the case of 1JEM, 2HID, and 1QFR, model 1 was selected as the starting structure from the ensemble of NMR structures. To obtain completely unphosphorylated HPr structures, phosphate groups present in the original structures were removed from 1JEM, 1FU0 chain $\mathrm{A}$, and 1FU0 chain B. Additional minor modifications of the models prior to the simulations included reversion of a Val51Met mutation in 1JEM and 2HID to match the wildtype sequence, as well as completion of those side chain 


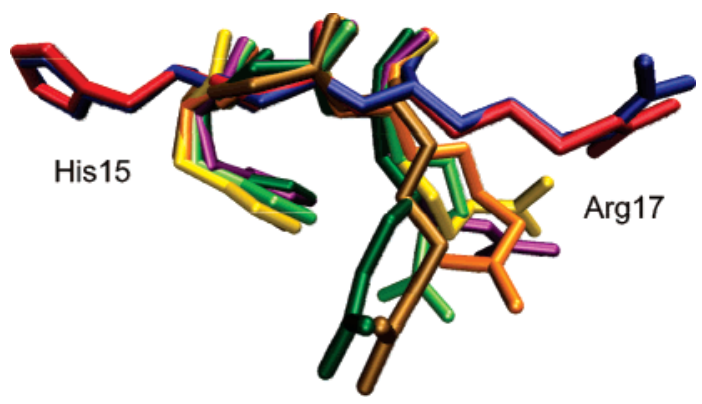

FIgURE 1: Representation of the His15 and Arg17 side chain positions in eight HPr structures from the Protein Data Bank. Amino acids 15-17 were superimposed by a least-squares fit of the backbone atoms. Hydrogen atoms as well as the side chain of residue 16 are not displayed for reasons of clarity. PDB structures are color-coded: 2HID (model 1), yellow; 2HPR, orange; 1FU0 (chain A), red; 1PTF, blue; 1QFR (model 1), dark green; 1KA5 (model 1), purple; 1QR5 (model 1), light green; and 1HDN (model $1)$, brown.

atoms of Lys83 that were missing in the crystal structure of 1PTF due to poor electron density. Superfluous atoms were deleted directly from the PDB files after an inspection with RASMOL (29), and new atoms were added with the LEAP module of AMBER7.0 (30). In the final step, two different protonation forms of each model, corresponding to singly protonated $\mathrm{His} 15$ ( $\mathrm{HPr}-\mathrm{His} 15_{\mathrm{H} \epsilon}$ ) or doubly protonated His15 ( $\left.\mathrm{HPr}-\mathrm{His} 15_{\mathrm{H} 2+}\right)$, were set using LEAP. The 12 created models (six structures in two protonation forms each) were used as starting structures for the MD simulations.

For His15-phosphorylated HPr, 1JEM (model 1) was used as the template. The phosphate group present in the PDB entry remained unchanged, while the Met51Val mutation was reverted to produce the wild-type structure. Parameters for the phosphohistidine residue had been calculated previously and were assigned as described in ref 24.

Molecular Dynamics Simulations. MD simulations were performed with the AMBER 7.0 suite of programs (30). To obtain neutral systems, $\mathrm{Na}^{+}$counterions were added to the model proteins. Each protein was placed in a periodic TIP3P water box (31) extending at least $10 \AA$ in all directions from the solute. Minimizations and MD calculations were carried out with SANDER using the parm99 force field $(32,33)$. The simulation strategy used was identical to the one described previously for simulations of HPr-Ser46P (34) and is therefore only specified here in brief. After energy minimization, the systems were equilibrated in a $130 \mathrm{ps}$ MD phase consisting of an $80 \mathrm{ps} \mathrm{MD}$ run in which the temperature was increased from 50 to $300 \mathrm{~K}$ and a $50 \mathrm{ps}$ simulation in which the density was adjusted to $1 \mathrm{~g} / \mathrm{cm}^{3}$. The subsequent MD production phase was carried out under NPT conditions ( 1 bar, $300 \mathrm{~K}$ ). The HPr-His $15_{\mathrm{H} \epsilon}$ and $\mathrm{HPr}-$ His $15_{\mathrm{H} 2+}$ model systems were simulated for a total of $5 \mathrm{~ns}$, and the HPr-His15P trajectory was recorded over a period of 9 ns. All simulations were performed using a time step of $1 \mathrm{fs}$ for the integration of the equations of motion. Snapshots of the systems were collected in time intervals of 1 ps during MD (including the equilibration phase). Analyses were performed with VMD (35), RASMOL (29), X-PLOR (36), PTRAJ (30), and SYBYL (37). A distance of less than $2.2 \AA$ and an $\mathrm{O} \cdots \mathrm{H}-\mathrm{N}$ angle of more than $150^{\circ}$ were used as hydrogen bond criteria (34). Interaction energies between the His15 side chain and other residues of HPr were calculated using a distance-dependent dielectric constant (36).

\section{RESULTS AND DISCUSSION}

PDB Structure Analysis. Previous structural studies have shown that the active site in HPr can exist in two distinct conformations that were termed OPEN and CLOSED. It has been a point of discussion whether this conformational switching is physiologically relevant $(11,21)$ or simply a result of the $\mathrm{pH}$ conditions under which the structures were studied $(13,18-20)$. Therefore, we examined 11 representative structures of unbound HPr from the PDB and analyzed their structural properties in light of the $\mathrm{pH}$ milieu in which they were acquired.

Structural overlays reveal that the His 15 side chain adopts two distinct conformations, while the side chain of the conserved residue Arg17 is rather flexible and can adopt numerous different conformations (Figure 1). On the basis of the distance between $\mathrm{N} \delta 1$ of His 15 and $\mathrm{N}$ of $\operatorname{Arg} 17$, we classified structures as CLOSED if this distance is $<4.5 \AA$ and as OPEN if this distance is $>7.5 \AA$ (Table 1). This distance criterion has the advantage of not being affected by the flexibility of the $\operatorname{Arg} 17$ side chain and gives results that are consistent with a previous classification based on the side chain distances of His15 and $\operatorname{Arg} 17(12,38)$. As can be seen in Table 1, unphosphorylated structures that were measured in an acidic milieu (1FU0 and 1PTF) show a

Table 1: Correlation among Active Site Conformation, $\mathrm{pH}$ Conditions, and Predominant Protonation Form for 11 Experimentally Determined HPr Structures

\begin{tabular}{lcclclcl}
\hline PDB entry & resolution $(\AA)$ & His15 phosphorylation & organism & $\mathrm{pH}^{a}$ & His15 form $^{b}$ & conformation $^{c}$ & H15-R17 distance $(\AA)^{\circ}$ \\
\hline 2HID (15) & NMR & no & B. subtilis & 6.9 & His15-H $\epsilon$ & CLOSED & 3.54 \\
2HPR (14) & 2.0 & no & B. subtilis & $\sim 7.0$ & His15-H $\epsilon$ & CLOSED & 3.91 \\
1KKM (23) & 2.8 & no & B. subtilis & 7.5 & His15-H $\epsilon$ & CLOSED & 3.89 \\
1FU0 (12) & 1.9 & no & En. faecalis & 4.2 & His15-H & OPEN & $8.75 / 7.57^{d}$ \\
1PTF (11) & 1.6 & no & En. faecalis & 5.0 & His15-H & OPEN & 8.87 \\
1QFR (13) & NMR & no & En. faecalis & 7.4 & His15-H $\epsilon$ & CLOSED & 3.59 \\
1KA5 (18) & NMR & no & S. aureus & 7.0 & His15-H $\epsilon$ & CLOSED & 3.81 \\
1QR5 (16) & NMR & no & S. carnosus & 7.14 & His15-H $\epsilon$ & CLOSED & 3.25 \\
1HDN (9) & NMR & no & E. coli & 6.5 & His15-H $\epsilon$ & CLOSED & 4.02 \\
1JEM (15) & NMR & yes & B. subtilis & 7.4 & His15 (P)-H $\epsilon$ & CLOSED & 3.82 \\
1PFH (10) & NMR & yes & E. coli & 7.5 & His15 (P)-H $\epsilon$ & CLOSED & 4.32 \\
\hline
\end{tabular}

${ }^{a} \mathrm{pH}$ of the crystallization medium or the NMR sample solution. ${ }^{b}$ Most populated protonation form of His 15 under the experimental conditions ${ }^{c}$ The conformation was defined on the basis of the His15 N $\delta 1-\operatorname{Arg} 17 \mathrm{~N}$ distance. Distances of $<4.5 \AA$ correspond to the CLOSED conformation and distances of $>7.5 \AA$ to the OPEN conformation. ${ }^{d}$ Distances for chains A and B, respectively; the smaller value in chain B is due to crystal packing (12). 

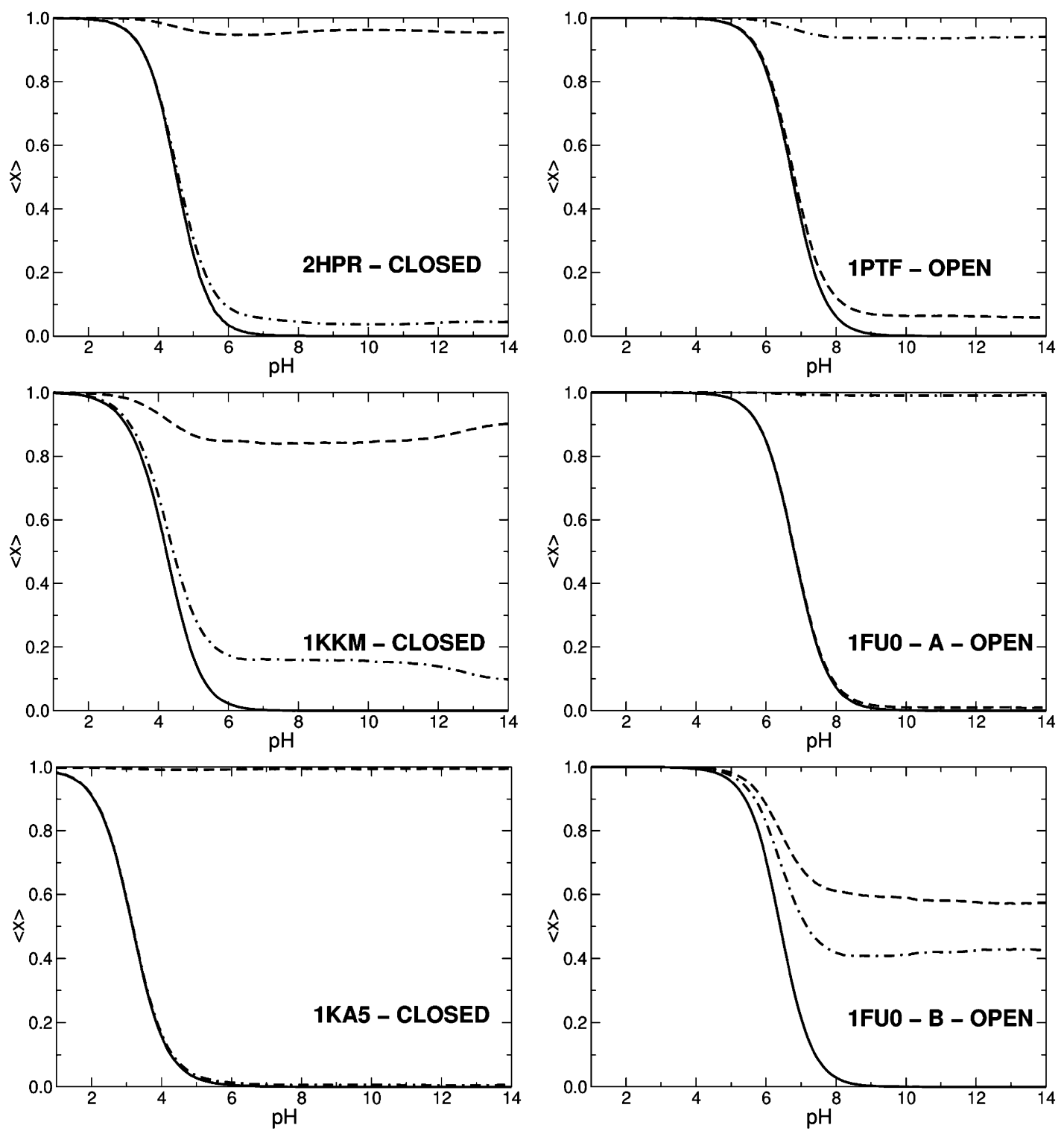

FIGURE 2: Protonation probabilities of His 15 in different experimentally determined HPr structures. The probability of the doubly protonated form $\left[\mathrm{His} 15_{\mathrm{H} 2+}(-)\right]$ as well as the $\delta$ - and $\epsilon$-tautomer of the singly protonated form His $15_{\mathrm{H} \delta}(-\cdot-)$ and His $15_{\mathrm{H} \epsilon}(---)$ is shown. It can be seen in the plots that for the CLOSED conformation the $\epsilon$-tautomer is favored while in the OPEN conformation the $\delta$-tautomer tends to be more populated. The protonation probability can be described by apparent $\mathrm{p} K_{\mathrm{a}}$ values between 3.2 and 4.5 for the CLOSED and between 6.4 and 6.8 for the OPEN conformation. Structural properties of the models and their apparent $\mathrm{p} K_{\mathrm{a}}$ values are given in Tables 1 and 2 , respectively.

distinct OPEN conformation of the active site, while the remaining structures that were determined at neutral $\mathrm{pH}$ exhibit a CLOSED conformation.

The phosphorylated HPr structures (1JEM and 1PFH) adopt a CLOSED conformation, and no OPEN form has been reported in the literature. The HPr-His15P structures will be analyzed separately later in this paper.

The predominant protonation state at the $\mathrm{pH}$ values of the experimental studies can be assigned on the basis of the experimentally determined $\mathrm{p} K_{\mathrm{a}}$ values. The unphosphorylated HPr proteins from B. subtilis, En. faecalis, E. coli, and $S$. aureus have His $15 \mathrm{p} K_{\mathrm{a}}$ values of 5.4 (39), 6.1 (40), 5.4 (41), and $5.8(40)$, respectively. Thus, it can be concluded that the 1FU0 and 1PTF structures, which were determined at low $\mathrm{pH}$, contain a doubly protonated $\mathrm{His}^{+}$ring, while the remaining structures of unphosphorylated $\mathrm{HPr}$ exhibit a singly protonated, uncharged His 15 . This observation suggests that the different protonation forms of His15 may account for the structural differences observed for unphosphorylated HPr.

Protonation Probability of His 15 in HPr. The calculated protonation probability curves of His 15 for different structures are shown in Figure 2. In the CLOSED conformation, the singly protonated form is primarily protonated at $\mathrm{N} \epsilon 2$, in contrast to the OPEN conformation, where $\mathrm{N} \delta 1$ is primarily protonated. The protonation probability can be described by an apparent $\mathrm{p} K_{\mathrm{a}}$ value between 3.2 and 4.5 for the CLOSED and between 6.4 and 6.8 for the OPEN conformation.

Thus, the protonation curve of His 15 is strongly shifted toward lower $\mathrm{pH}$ values in the CLOSED structures (2HPR, $1 \mathrm{KKM}$, and 1KA5) compared to a typical histidine within a peptide segment in solution where the titration behavior can be described by an apparent $\mathrm{p} K_{\mathrm{a}}$ value of $\sim 7.0$ (42). By contrast, in the OPEN structures (1PTF, 1FU0 chain A, and 1FU0 chain B), the protonation curve is nearly unshifted. 
Table 2: Energy Decomposition of Apparent $\mathrm{p} K_{\mathrm{a}}$ Values into Born $\left(\Delta G_{\mathrm{Born}}\right)$, Background $\left(\Delta G_{\text {back }}\right)$, Model $\left(\Delta G_{\text {model }}\right)$, and Mean-Field Interaction $\left(\left\langle\Delta G_{\text {inter }}\right\rangle\right)$ Energy Differences of His15 Tautomers in Kilocalories per Mole ${ }^{a}$

\begin{tabular}{|c|c|c|c|c|c|c|c|}
\hline structure & $\Delta G_{\text {Born }}$ & $\Delta G_{\text {back }}$ & $\left\langle\Delta \bar{G}_{\text {inter }}\right\rangle$ & $\Delta G_{\text {model }^{b}}$ & sum & $\mathrm{p} K_{\text {app }}$ & conformation \\
\hline 2HPR & 1.6 & 0.1 & 1.2 & -9.1 & -6.2 & 4.5 & CLOSED \\
\hline 1KA5 & 2.2 & 1.8 & 0.7 & -9.1 & -4.3 & 3.2 & CLOSED \\
\hline $1 \mathrm{KKM}$ & 1.6 & 0.3 & 1.3 & -9.1 & -5.9 & 4.2 & CLOSED \\
\hline 1PTF & 1.6 & -1.4 & 0.1 & -9.6 & -9.3 & 6.8 & OPEN \\
\hline $1 \mathrm{FU} 0$ chain $\mathrm{A}$ & 2.4 & -2.2 & -0.1 & -9.6 & -9.5 & 6.8 & OPEN \\
\hline 1FU0 chain B & 1.2 & -0.7 & -0.1 & -9.6 & -9.3 & 6.4 & OPEN \\
\hline
\end{tabular}

${ }^{a}$ The mean-field interaction energy is calculated using probabilities at the $\mathrm{pH}$ equal to the apparent $\mathrm{p} K_{\mathrm{a}}$ value. The deprotonation was calculated to occur at $\mathrm{N} \epsilon 2\left(\mathrm{His} 15_{\mathrm{H} 2+}-\mathrm{His} 15_{\mathrm{H} \delta}\right.$ ) for $1 \mathrm{PTF}$ as well as $1 \mathrm{FU} 0$ and at $\mathrm{N} \delta 1$ (His $15_{\mathrm{H} 2+}-\mathrm{His} 15_{\mathrm{H} \epsilon}$ ) for the other structures. ${ }^{b} \Delta G_{\mathrm{model}}=-R T$ ln $10 \mathrm{p} K_{\mathrm{a} \text {, model }}$ with $\mathrm{p} K_{\mathrm{a} \text {, model }}$ values of 7.0 and 6.6 for $\mathrm{N} \epsilon 2$ and $\mathrm{N} \delta 1$, respectively.

The larger deviation of the apparent $\mathrm{p} K_{\mathrm{a}}$ of $1 \mathrm{KA} 5$ (NMR) compared to 2HPR and 1KKM (X-ray) in Table 2 can likely be attributed to the poor definition of the charged Arg17 side chain relative to His 15 . The $\mathrm{p} K_{\text {app }}$ values independently obtained for the different crystal structures, however, agree quite well, suggesting that the structures are generally sufficiently accurate and no further refinement (e.g., by molecular dynamics simulations) is required prior to analysis.

To understand the origin of the $\mathrm{p} K_{\mathrm{a}}$ shift, we decomposed this shift into its energy contributions. The result of this decomposition is listed in Table 2 . We consider three different energy contributions: $\Delta G_{\text {Born }}, \Delta G_{\text {back }}$, and $\left\langle\Delta \bar{G}_{\text {inter }}\right\rangle$. The term $\Delta G_{\text {Born }}$ describes the energy contribution due to the changed solvent polarization of an isolated amino acid compared to an amino acid in the protein. The term $\Delta G_{\text {back }}$ describes the energy shift due to the interaction with nontitrating residues of the protein. The term $\left\langle\Delta \bar{G}_{\text {inter }}\right\rangle$ describes the mean-field interaction of His 15 with all the different titratable residues in the protein. As one can see in Table 2, the term $\Delta G_{\text {Born }}$ cannot explain the different titration behavior of the OPEN conformation and the CLOSED conformation. In contrast, the terms $\Delta G_{\text {back }}$ and $\left\langle\Delta \bar{G}_{\text {inter }}\right\rangle$ show a clear trend. $\Delta G_{\text {back }}$ is negative for the OPEN conformation and positive for the CLOSED conformation. $\left\langle\Delta \bar{G}_{\text {inter }}\right\rangle$ is close to zero for the OPEN conformation and positive for the CLOSED conformation. Figure S1 of the Supporting Information shows the contributions of all titratable residues to $\left\langle\Delta \bar{G}_{\text {inter }}\right\rangle$ for $2 \mathrm{HPR}$ and $1 \mathrm{PTF}$ as a representative for the CLOSED and OPEN conformation, respectively. The mean interaction energies of His 15 are clearly dominated by the interaction with $\operatorname{Arg} 17$ in the CLOSED conformation, while this interaction is negligible in the OPEN conformation.

Microstate Model for the Protonation and Conformational Forms of His 15. The calculated apparent $\mathrm{p} K_{\mathrm{a}}$ values of His 15 between 3.2 and 4.5 for the CLOSED and between 6.4 and 6.8 for the OPEN conformation of unphosphorylated $\mathrm{HPr}$ (Table 2) differ from experimental $\mathrm{p} K_{\mathrm{a}}$ values which are between 5.4 and 6.1. However, in the calculations described above, only either the CLOSED or the OPEN conformation was considered, while in experiments, both conformations are in a $\mathrm{pH}$-dependent equilibrium. In a more realistic scenario, the conformational equilibrium between the CLOSED conformation and the OPEN conformation needs to be included.

To determine whether the protonation of His 15 can be considered independently, the correlation of the His15 protonation with the protonation of other residues was

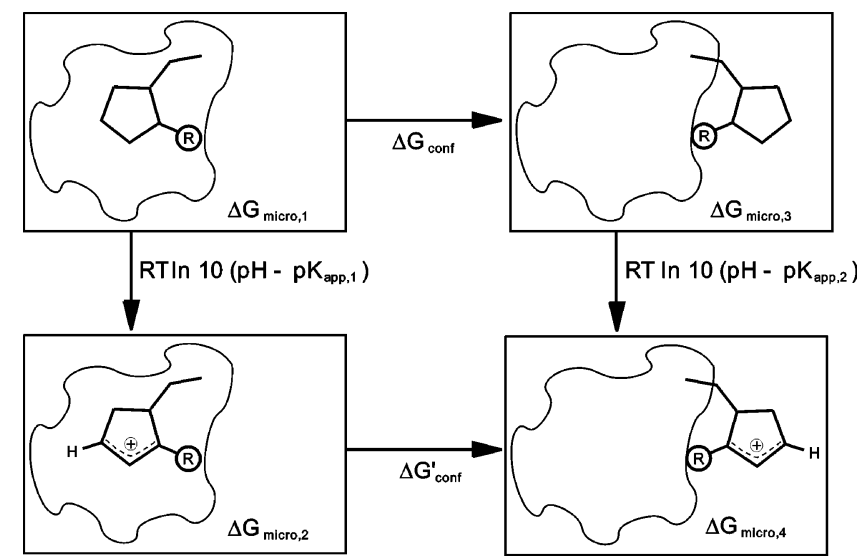

FIGURE 3: Thermodynamic cycle with schematic pictures of the four microstates in a simple model. The moiety $\mathrm{R}$ is a hydrogen atom in HPr-His 15 or a phosphate group in HPr-His15P. In the presence of two protons (HPr-His15) or a proton and a phosphate group (HPr-His15P), the imidazole ring carries a positive charge, indicated by the plus sign in the respective states. The relative population of the histidine tautomers is not included.

analyzed. A strong correlation requires both a large interaction energy and two residues titrating in the same $\mathrm{pH}$ range $(43,44)$. Our calculations show that the only residue that interacts strongly with His15 is Arg17, which titrates at a much higher $\mathrm{pH}$. Thus, the protonation of His 15 can be considered independently, and a four-microstate model can be used to calculate the protonation probability of His15, considering two protonation forms (doubly and singly protonated) and two conformations (OPEN and CLOSED) of His 15.

The four microstates of the protein are as follows: (1) singly protonated, CLOSED conformation; (2) doubly protonated, CLOSED conformation; (3) singly protonated, OPEN conformation; and (4) doubly protonated, OPEN conformation (Figure 3). If the first state is chosen as the reference state, the energies of the four microstates are given by

$$
\begin{aligned}
& \Delta G_{\text {micro, } 1}=0 \\
& \Delta G_{\text {micro, } 2}=R T \ln 10\left(\mathrm{pH}-\mathrm{p} K_{\text {app }, 1}\right) \\
& \Delta G_{\text {micro }, 3}=\Delta G_{\text {conf }} \\
& \Delta G_{\text {micro }, 4}=\Delta G_{\text {conf }}+R T \ln 10\left(\mathrm{pH}-\mathrm{p} K_{\text {app }, 2}\right)
\end{aligned}
$$

$\Delta G_{\text {conf }}$ is the energy difference between the OPEN and CLOSED conformation when His 15 is singly protonated. It 
contains the torsional energy of the $\chi_{1}$ and $\chi_{2}$ angles of His 15 , but also all other strains in the structure building up or relaxing upon the conformational change. $\mathrm{p} K_{\text {app }, 1}$ is the $\mathrm{p} K_{\mathrm{a}}$ value of His 15 in the CLOSED conformation, and $\mathrm{p} K_{\mathrm{app}, 2}$ is the $\mathrm{p} K_{\mathrm{a}}$ value of His 15 in the OPEN conformation.

The population of microstate $n$ is given by

$$
\left\langle x_{n}\left(\Delta G_{\text {conf }}, \mathrm{pH}\right)\right\rangle=\frac{\exp \left(\frac{-\Delta G_{\text {micro }, n}}{R T}\right)}{\sum_{m=1}^{4} \exp \left(\frac{-\Delta G_{\text {micro }, m}}{R T}\right)}
$$

The probability of the CLOSED conformation equals

$$
\begin{aligned}
&\left\langle p_{\text {CLOSED }}\left(\Delta G_{\text {conf }}, \mathrm{pH}\right)\right\rangle=\left\langle x_{1}\left(\Delta G_{\text {conf }}, \mathrm{pH}\right)\right\rangle+ \\
&\left\langle x_{2}\left(\Delta G_{\text {conf }}, \mathrm{pH}\right)\right\rangle
\end{aligned}
$$

In Figure 4, the resulting probability of the CLOSED conformation (Figure 4A) and population of the four microstates (Figure $4 \mathrm{C}-\mathrm{F}$ ) are plotted. The conformational energy $\Delta G_{\text {conf }}$ was estimated from the experimental $\mathrm{p} K$ values of B. subtilis (5.4) and En. faecalis (6.1) for His15 of HPr by the relationships $\left\langle p_{\text {CLOSED }}=\left(\Delta G_{\text {conf }}, 5.4\right)\right\rangle$ and $\left\langle p_{\text {CLOSED }}\right.$ $\left.=\left(\Delta G_{\mathrm{conf}}, 6.1\right)\right\rangle$, respectively. Solving the equation leads to conformational energies $\left(\Delta G_{\text {conf }}\right)$ of 1.8 and $0.7 \mathrm{kcal} / \mathrm{mol}$, respectively (marked by dashed lines in Figure 4). The $\mathrm{p} K_{\text {app, }, 1}$ value of 4.5 (2HPR, CLOSED) and the $\mathrm{p} K_{\mathrm{app}, 2}$ value of 6.8 (1PTF, OPEN) used for the plots were obtained from calculations at atomic detail for the highest-resolution crystal structures available (Table 2). Therefore, it was assumed that the apparent $\mathrm{p} K_{\mathrm{a}}$ values may contain a small error due to the structure used as input for the calculation, while the error of the theoretical method should be rather constant. Any combination of $\mathrm{p} K_{\mathrm{app}, 1}$ (from CLOSED) and $\mathrm{p} K_{\mathrm{app}, 2}$ (from OPEN) will not change the conclusions about the OPENto-CLOSED transition, only the value estimated for $\Delta G_{\text {conf. }}$.

At $\mathrm{pH} 7$ and a positive conformational energy, the singly protonated and CLOSED microstate (Figure 4C) is favored, while at lower $\mathrm{pH}$, the doubly protonated and OPEN microstate (Figure 4F) is favored. To populate the two remaining microstates (CLOSED, doubly protonated, and OPEN, singly protonated), very large positive conformational energies, stabilizing the CLOSED conformation in the doubly protonated form, or negative conformational energies, stabilizing the OPEN conformation, are required.

Thus, we obtain a simple picture of our system from this model. His 15 of HPr has two conformations: a CLOSED conformation with a low apparent $\mathrm{p} K_{\mathrm{a}}$ value, which is populated in the singly protonated form, and an OPEN conformation with a high apparent $\mathrm{p} K_{\mathrm{a}}$ value, which is populated in the doubly protonated form. The experimental $\mathrm{p} K_{\mathrm{a}}$ value describes a mixture of both conformations which causes the $\mathrm{p} K_{\mathrm{a}}$ value to be between the values for the OPEN and the CLOSED conformation. The CLOSED $\rightarrow$ OPEN transition in the singly protonated form requires His 15 to adopt a less favorable conformation with a higher energy, but this energy is compensated by the favorable energetic consequences of protonation of this residue. To test this interdependence between the protonation state and the conformation, molecular dynamics simulations starting from different HPr conformations and protonation forms were performed.

MD Simulations of Unphosphorylated HPr-His $15_{H \epsilon}$ and $\mathrm{HPr}$-His $15_{\mathrm{H} 2+}$. For the MD simulations, six PDB structures of $\mathrm{HPr}$ (three of them in the OPEN and three in the CLOSED conformation) were modeled either with $\mathrm{N} \epsilon 2$-protonated His 15 (HPr-His $15_{\mathrm{H} \epsilon}$ ) or with doubly protonated His 15 (HPrHis $\left.15_{\mathrm{H} 2+}\right)$. Stable trajectories were obtained in the $5 \mathrm{~ns}$ MD simulations, and the backbone rmsd was for all systems below $1.6 \AA$ compared to the starting structure of the MD production phase. This small deviation indicates that no major structural changes have taken place in the HPr models during simulation. Visual inspections of the structures recorded at the end of the MD production phase proved that the arrangement of the secondary structure elements as well as the overall tertiary fold was maintained in all proteins. Comparisons of the HPr-His $15_{\mathrm{H} \epsilon}$ and $\mathrm{HPr}-\mathrm{His} 15_{\mathrm{H} 2+}$ simulations also revealed that the differences in the protonation form do not affect the overall structure or dynamics of HPr.

A detailed analysis of the arrangement of the amino acids in the active center showed, however, that the residues in the vicinity of the active site adopt different spatial arrangements during the $\mathrm{HPr}-\mathrm{His} 15_{\mathrm{H} \epsilon}$ and $\mathrm{HPr}-\mathrm{His} 15_{\mathrm{H} 2+}$ simulations (Figure 5). Therefore, the active site conformations were analyzed by plotting the His $15 \mathrm{~N} \delta 1-\operatorname{Arg} 17 \mathrm{~N}$ distance as a function of the simulation time (Figure 6). It is evident from the characteristic distances of approximately 4 and $8 \AA$ that the structures adopt either an OPEN or a CLOSED conformation. Further inspection of the simulations also shows that there is a clear correlation between the active site conformation and the His15 protonation form.

Simulations for a singly protonated His 15 that started from CLOSED structures (Figure 6A, black lines) predominantly remained in the CLOSED conformation over the simulation time. There are only minor fluctuations for the 1JEM and 2HID simulation after simulation times of $\sim 4.5$ and $\sim 1 \mathrm{ns,}$ respectively. Analogously, a stable active site conformation was also observed for those simulations that started from an OPEN conformation with a doubly protonated His15 (Figure $6 \mathrm{~B}$, gray lines).

In contrast, a CLOSED $\rightarrow$ OPEN transition is observed for all systems starting from a CLOSED conformation with a doubly protonated histidine (Figure 6A, gray lines), while the opposite transition is observed for those systems that started from an OPEN conformation with a singly protonated histidine (Figure 6B, black lines). In some simulations, this transition is very fast and occurs in the equilibration stage of the simulations (e.g., 1JEM simulation). For the other systems, the transitions occur in the time interval from 0.4 to $1.5 \mathrm{~ns}$.

All OPEN $\rightarrow$ CLOSED transitions that were detected start from an initially fully OPEN active site $(d>7.5 \AA)$ and run through a semi-OPEN state (Figure 6B) that is characterized by a His $15 \mathrm{~N} \delta 1-\operatorname{Arg} 17 \mathrm{~N}$ distance of approximately 6-7 $\AA$. This semi-OPEN conformation was reached within the minimization or equilibration phase of the respective HPrHis $15_{\mathrm{H} \epsilon}$ simulations and remained stable for $\sim 0.5-1.5 \mathrm{~ns}$ before a CLOSED conformation was adopted. The occurrence of a semi-OPEN state is consistent with the results of van Nuland et al. (10), who observed structural changes of the OPEN active site conformation in En. faecalis HPr (PDB 


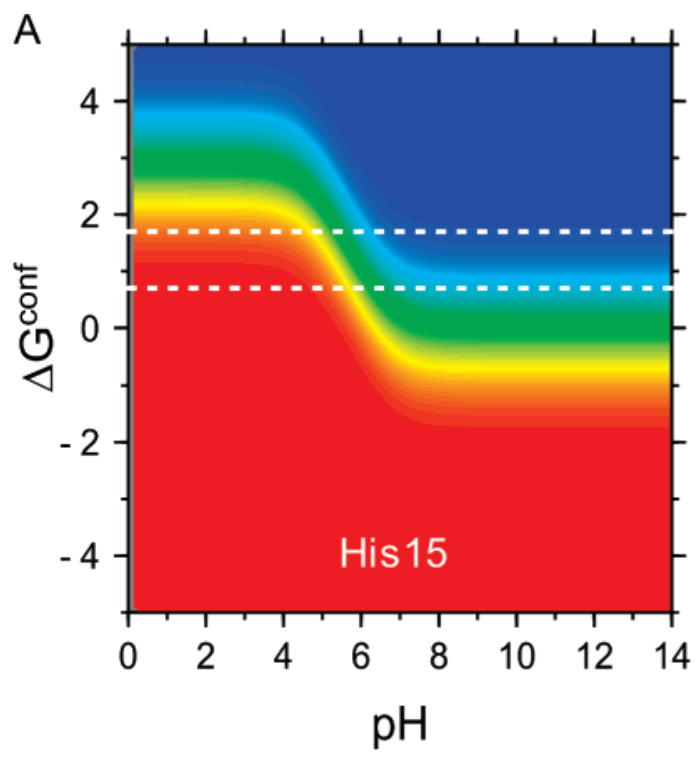

CLOSED

\begin{abstract}
protonation
\end{abstract}
form

His15
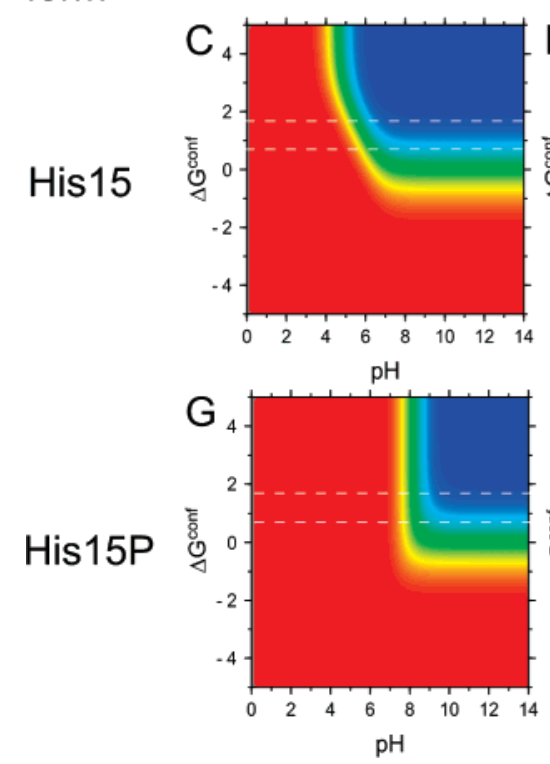

B

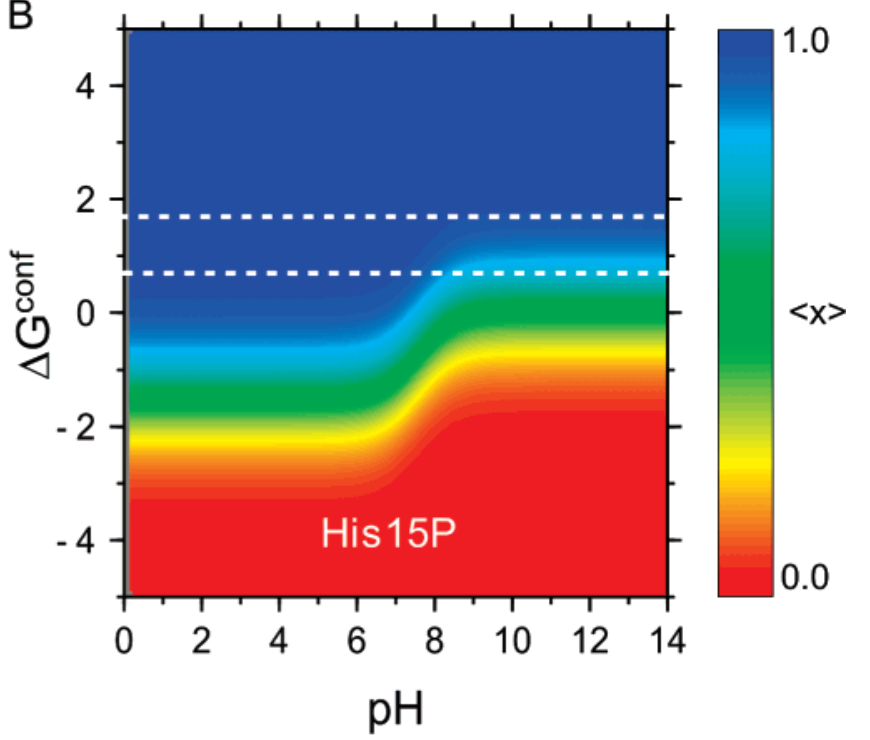

OPEN
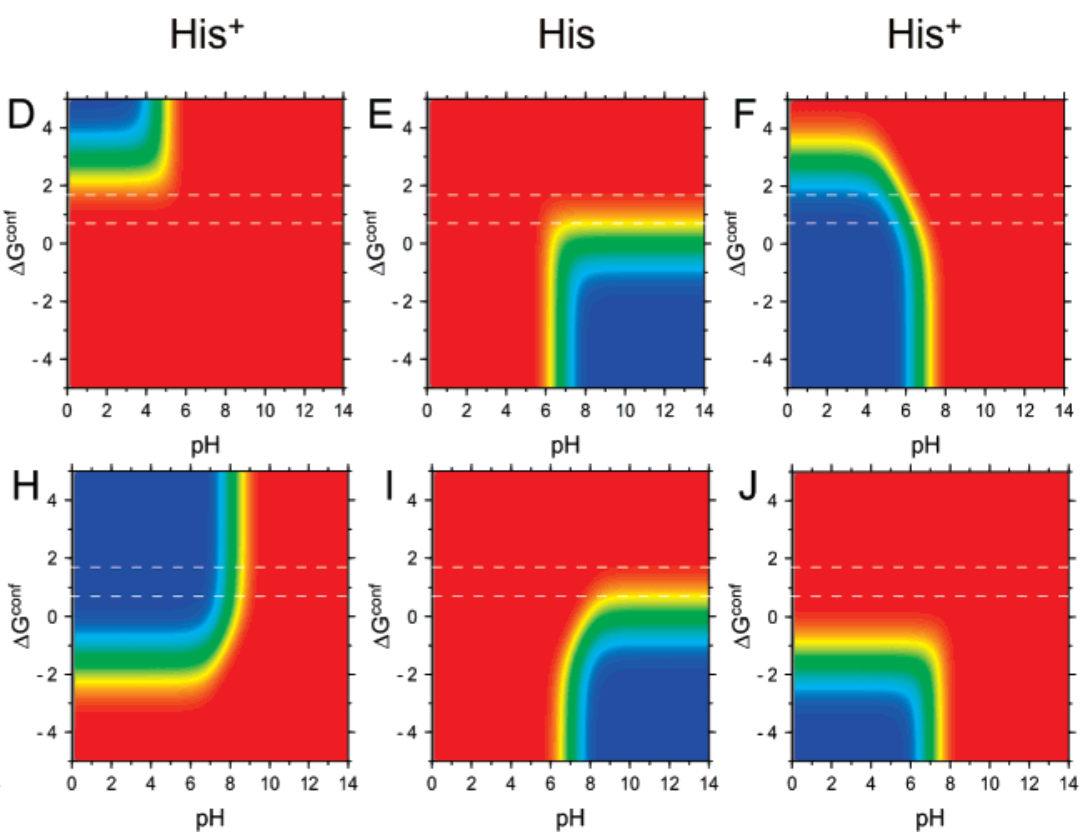

FIGURE 4: Probability plots of the four-microstate model of His15 (A and C-F) and His15P (B and G-J) (blue for 100\% probability, green for $50 \%$ probability, and red for $0 \%$ probability). For His 15 , apparent $\mathrm{p} K_{\mathrm{a}}$ values of 4.6 and 6.8 were used, corresponding to the protonation energy of the CLOSED form in $2 \mathrm{HPR}$ and the OPEN form in 1PTF, respectively. For His $15 \mathrm{P}$, apparent $\mathrm{p} K_{\mathrm{a}}$ values of 8.0 and 7.0 were used, resembling the experimental protonation energy of His15P in the CLOSED conformation and the model $\mathrm{p} K_{\mathrm{a}}$ value for phosphorylated histidine in solution. (A) Probability of the CLOSED conformation (both protonation forms) of His15. (B) Probability of the CLOSED conformation (both protonation forms) of His15P. The conformational energy $\left(\Delta G_{\text {conf }}\right)$ is given in kilocalories per mole. $(\mathrm{C}-\mathrm{F})$ Probability of the CLOSED $(\mathrm{C}$ and $\mathrm{D})$ and OPEN (E and F) conformation of HPr-His15 for each of the two different protonation forms (denoted as His and His ${ }^{+}$, respectively). (G-J) Probability of the CLOSED (G and H) and OPEN (I and J) conformation of HPrHis 15P for each of the two different protonation forms (denoted as His and His ${ }^{+}$, respectively). The conformational energies $\left(\Delta G_{\text {conf }}\right)$ of 0.7 and $1.8 \mathrm{kcal} / \mathrm{mol}$ discussed in the text are marked by dashed horizontal lines.

entry 1PTF) during 0.2 ns unrestrained MD with uncharged, singly protonated His15, but no complete transition to a CLOSED conformation. The results of our simulations indicate that a complete structural OPEN $\rightarrow$ CLOSED transition requires at least $0.5 \mathrm{~ns}$ (Figure 6B), and therefore, $0.2 \mathrm{~ns} \mathrm{MD}$ are most likely too short for the observation of this effect.

Taking together the results from the microstate model calculations and the MD simulations, our data show that OPEN and CLOSED conformations are clearly associated with distinct protonation forms. The reciprocal protonation forms, which are predicted to be unstable according to the microstate model, cause structural conversion in the MD simulations.

Interactions of His15 in Different Conformations and Protonation Forms. To identify those interactions that cause the OPEN $\leftrightarrow$ CLOSED transition, trajectories of two En. faecalis HPr structures, which show the respective changes, were analyzed in more detail. The simulation of the 1QFR HPr-His $15_{\mathrm{H} 2}+$ model (Figure 6A, bottom panel, gray line) was used to study the CLOSED $\rightarrow$ OPEN transition via analysis of the interaction energies of $\mathrm{His} 15_{\mathrm{H} 2+}$ for two time 

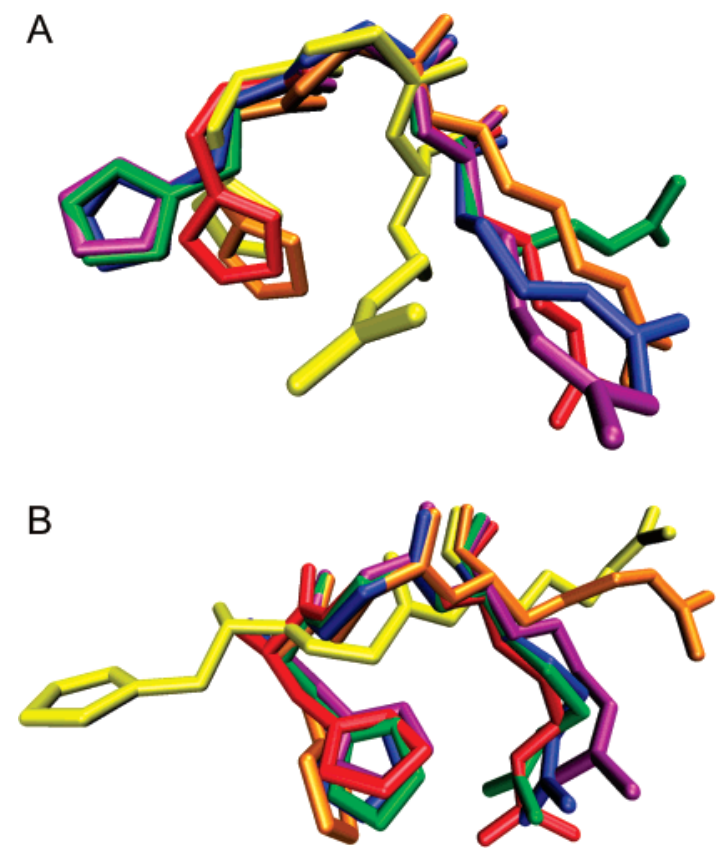

FIGURE 5: Snapshots of HPr structures undergoing an OPEN $\leftrightarrow$ CLOSED transition during MD simulation. (A) CLOSED $\rightarrow$ OPEN transition of 1QFR ( $\left.\mathrm{HPr}-\mathrm{His} 15_{\mathrm{H} 2+}\right)$. Overlay of the initial structure (yellow) and structures recorded after 0.5 (orange), 1.0 (red), 1.5 (blue), 2.0 (purple), and $2.5 \mathrm{~ns}$ (green). (B) OPEN $\rightarrow$ CLOSED transition of 1PTF $\left(\mathrm{HPr}-\mathrm{His} 15_{\mathrm{H} \epsilon}\right)$. Overlay of structures recorded after 0.0 (yellow), 0.5 (orange), 1.0 (red), 1.5 (blue), 2.0 (purple), and $2.5 \mathrm{~ns}$ (green). Backbone atoms of amino acids 12-17 were fitted by a least-squares algorithm. Amino acids 15 and 17 are shown in detail. Hydrogen atoms and the Thr16 side chain are not displayed for reasons of clarity.

intervals corresponding to the CLOSED and OPEN conformation, respectively (Figure 7A). The diagram indicates that opening is mainly favored by stronger attractive interactions between $\mathrm{His} 15_{\mathrm{H} 2+}$ and residues $11-14$, as well as weaker repulsive interactions between His $15_{\mathrm{H} 2+}$ and Arg 17. These interactions which favor the OPEN conformation are partially counterbalanced by the Glu84-His $15_{\mathrm{H} 2+}$ interaction, resulting in an only small overall energetic difference between both conformations. The fact that the repulsion between His 15 and Arg17 is at least partially retained in the OPEN conformation is also evident from the relative side chain orientation in the static structures and during the MD simulations. Although the Arg17 side chain fluctuates significantly compared to the side chains of the other active site residues, its average position is significantly shifted away from His 15 in the doubly protonated compared to the singly protonated simulations (Figure 5).

To study the OPEN $\rightarrow$ CLOSED transition, the interactions of His $15_{\mathrm{H} \epsilon}$ in the 1PTF simulation (Figure 6B, bottom panel, black line) were analyzed as described above. The OPEN conformation shows only weak attractive interactions of His $15_{\mathrm{H} \epsilon}$ with residues Gly13, Ile14, and Met51, while the CLOSED conformation is significantly stabilized by strong attractive interactions of His $15_{\mathrm{H} \epsilon}$ with Arg 17 and its adjacent residues (Figure 7B). As the stability of the CLOSED active site conformation of $\mathrm{HPr}-\mathrm{His} 15_{\mathrm{H} \epsilon}$ is mainly based on the favorable interaction between His 15 and $\operatorname{Arg} 17$, the results of the study suggest that $\operatorname{Arg} 17$ is essential for the predominance of the CLOSED form of HPrHis $15_{\mathrm{H} \epsilon}$. Due to the significant role of residue 17 , the interaction energy was further dissected into His $15_{\text {side chain }}-$ $\operatorname{Arg} 17_{\text {backbone }}$ and His $15_{\text {side chain }}-\operatorname{Arg} 17_{\text {side chain }}$ interactions.

From the bar chart in Figure S2 of the Supporting Information, it becomes obvious that the interaction energy between the His 15 side chain and the Arg17 backbone atoms is generally larger than the interaction energy between the side chains of the two residues. Visual inspections of the active centers of several $\mathrm{HPr}-\mathrm{His} 15_{\mathrm{H} \epsilon}$ snapshots with a CLOSED active site revealed that the imidazole $\mathrm{N} \delta 1$ is often close in space to the Arg 17 backbone amide hydrogen atom. A highly favorable electrostatic interaction between the two atoms was detected in detailed energy calculations. The attractive force between Arg17 H and His15 N $\delta 1$ (6.8 kcal/ mol) was considerably larger than all other attractive interactions between the His 15 side chain and the Arg17 backbone atoms. Thus, it can be assumed that the favorable interaction between His15 and Arg17 that stabilizes the CLOSED form of HPr-His $15_{\mathrm{H} \epsilon}$ is mainly due to an attractive electrostatic interaction between $\mathrm{N} \delta 1$ and the backbone amide hydrogen of amino acid 17. The fact that the side chain of residue 17 has an only minor stabilizing effect (Figure S2) on the HPr conformation itself suggests that its strict conservation is rather required for interactions with the HPr binding partners. Inspection of the HPrEnzyme I complex structure (45) shows that Arg17 actually forms a salt bridge with Glu67 and Glu68 of enzyme I (EI). The high flexibility of Arg17 in free HPr is consistent with the observation that the $\operatorname{Arg} 17$ side chain orientation is significantly changed upon formation of the HPr-EI complex.

His15-Phosphorylated HPr: $p K_{a}$ Value, MD Simulation, and Energy Analysis. According to the analysis of the experimentally determined structures (Table 1), HPr-His15P adopts a CLOSED conformation, which is highly similar to that observed in unphosphorylated HPr (Figure 8). Interestingly, experimental data also show that His $15 \mathrm{~N} \delta 1$-phosphorylated HPr exhibits significantly higher $\mathrm{p} K_{\mathrm{a}}$ values of 7.7-8.3 $(5,39)$ compared to the unphosphorylated form, drastically increasing the portion of HPr with a charged His ring at physiological $\mathrm{pH}$. Since a positively charged imidazole group was shown to force the OPEN conformation in unphosphorylated HPr, the observation of a CLOSED conformation for negatively charged HPr-His $15 \mathrm{P}$ is rather unexpected.

Therefore, the aim of the subsequent analysis was to identify the structural properties responsible for the high $\mathrm{p} K_{\mathrm{a}}$ value and to discover those interactions that stabilize the CLOSED conformation. The apparent $\mathrm{p} K_{\mathrm{a}}$ values and meanfield interaction energies were calculated for seven models taken from an ensemble of 25 NMR structures of phosphorylated $\mathrm{HPr}$. The apparent $\mathrm{p} K_{\mathrm{a}}$ values are in the range from 5.8 to 7.3 (Table 3) which is considerably lower than the experimental $\mathrm{p} K_{\mathrm{a}}$ values of approximately 7.7-8.3 (5).

We previously observed a similar discrepancy between experimental and calculated apparent $\mathrm{p} K_{\mathrm{a}}$ values for unphosphorylated HPr and could attribute it to the conformational equilibrium between the OPEN and CLOSED conformation. For phosphorylated HPr, however, this explanation is not appropriate, since even the protonated form was experimentally shown to adopt the CLOSED conformation $(10,15)$. Thus, the discrepancies between experimental and calculated $\mathrm{p} K_{\mathrm{a}}$ values might rather result from local inaccuracies of the analyzed structures. One inherent source of such inaccuracies 

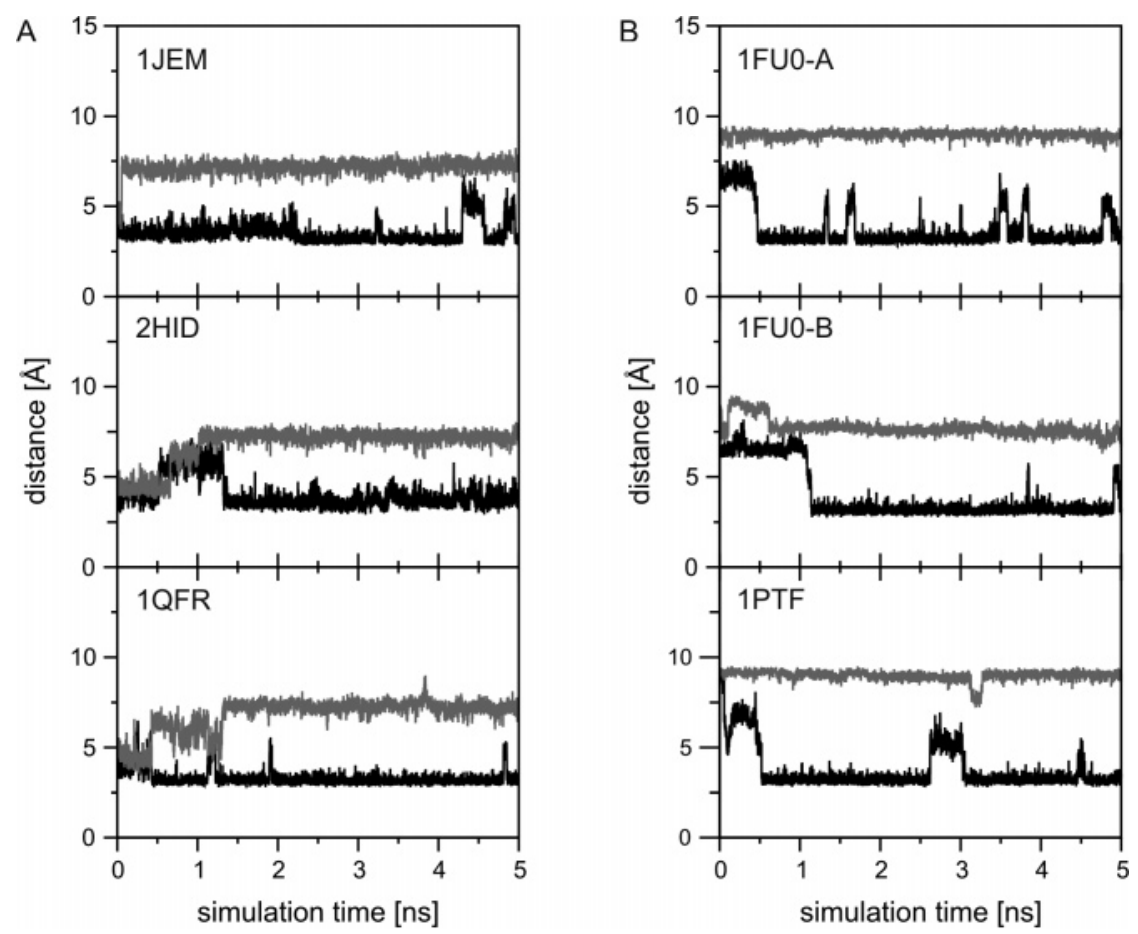

FIGURE 6: Orientation of His15 during the MD simulation for different protonation forms. The His $15 \mathrm{~N} \delta 1-\operatorname{Arg} 17 \mathrm{~N}$ distance is plotted as a function of the simulation time. The first $130 \mathrm{ps}$ period represents the equilibration phase of the 5 ns MD simulations. Simulations corresponding to singly or doubly protonated His 15 are indicated by black and gray lines, respectively. (A) Simulations for models $1 \mathrm{JEM}$ (top), 2HID (middle), and 1QFR (bottom). The opening motion for the His $15_{\mathrm{H} 2}+$ simulation is evident for all systems (gray line). (B) Simulations for models 1FU0 chain A (top), 1FU0 chain B (middle), and 1PTF (bottom). The closing motion for the His15 $\mathrm{H} \epsilon$ simulation is evident for all systems (black line).
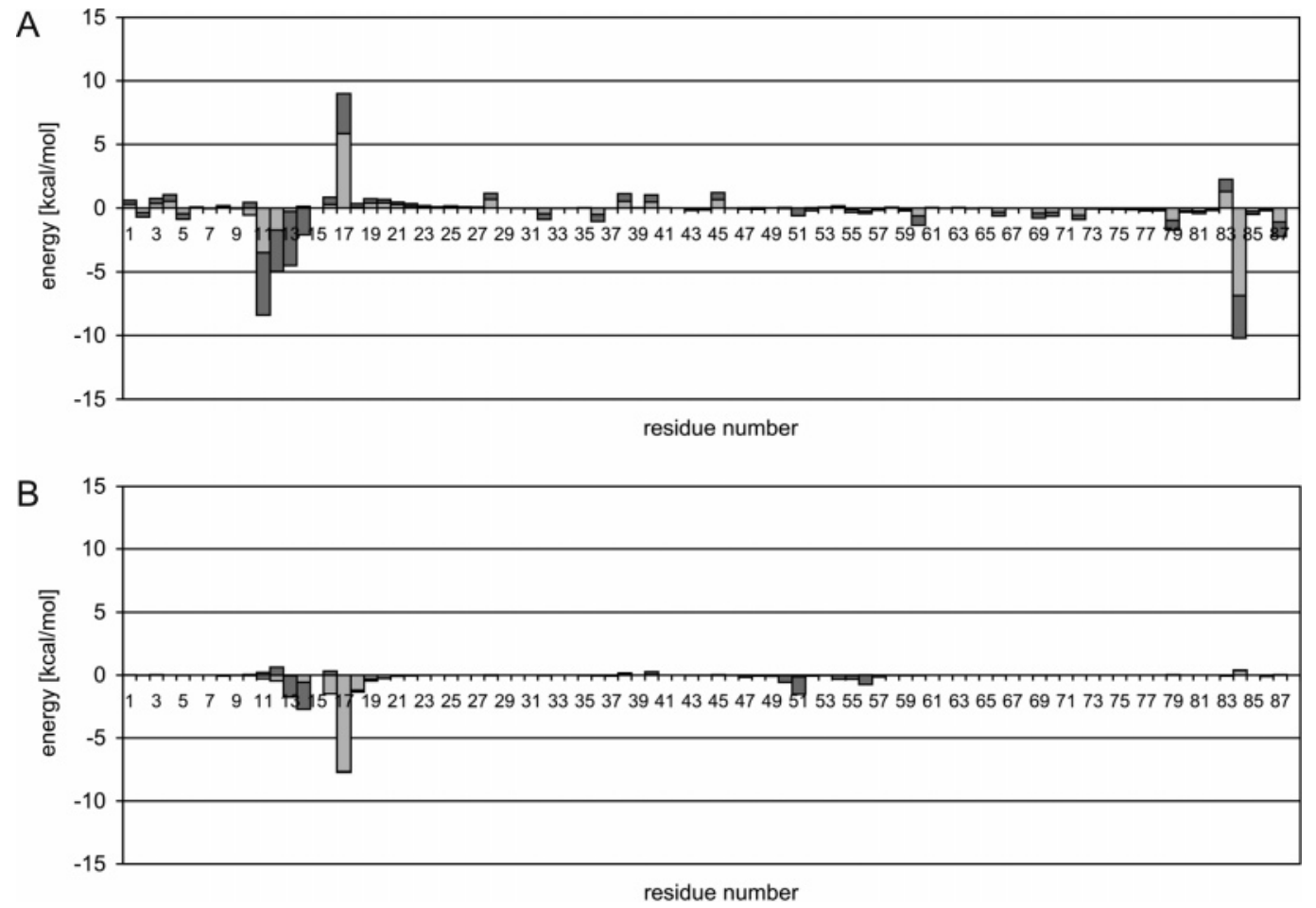

FIGURE 7: Comparison of average total interaction energies between the His 15 side chain and all other amino acids for $\mathrm{HPr}-\mathrm{His} 15_{\mathrm{H} 2+}(\mathrm{A})$ and HPr-His $15_{\mathrm{H} \epsilon}(\mathrm{B})$ in the OPEN (dark gray) and CLOSED (light gray) conformation. The bars are shown as stacked plots. Calculations for $\mathrm{HPr}-\mathrm{His} 15_{\mathrm{H} 2+}$ are based on structures recorded during $250 \mathrm{ps}$ time intervals of the 1QFR HPr-His $15_{\mathrm{H} 2+}$ simulation: $0-0.25 \mathrm{~ns}$ for CLOSED and 2-2.25 ns for OPEN. Energies for HPr-His $15_{\mathrm{H} \epsilon}$ were determined using the structures collected during $25 \mathrm{ps}$ periods of the 1PTF HPr-His $15_{\mathrm{H} \epsilon}$ simulation: $0-25$ ps for OPEN and 1000-1025 ps for CLOSED.

in the determination of the NMR structure of phosphorylated proteins is the lack of direct NOE distance restraints for the phosphate group. Additionally, neither electrostatic interac- tions nor water molecules were included in the NMR refinement, which again might in particular cause problems for highly charged phosphorylated amino acids. 

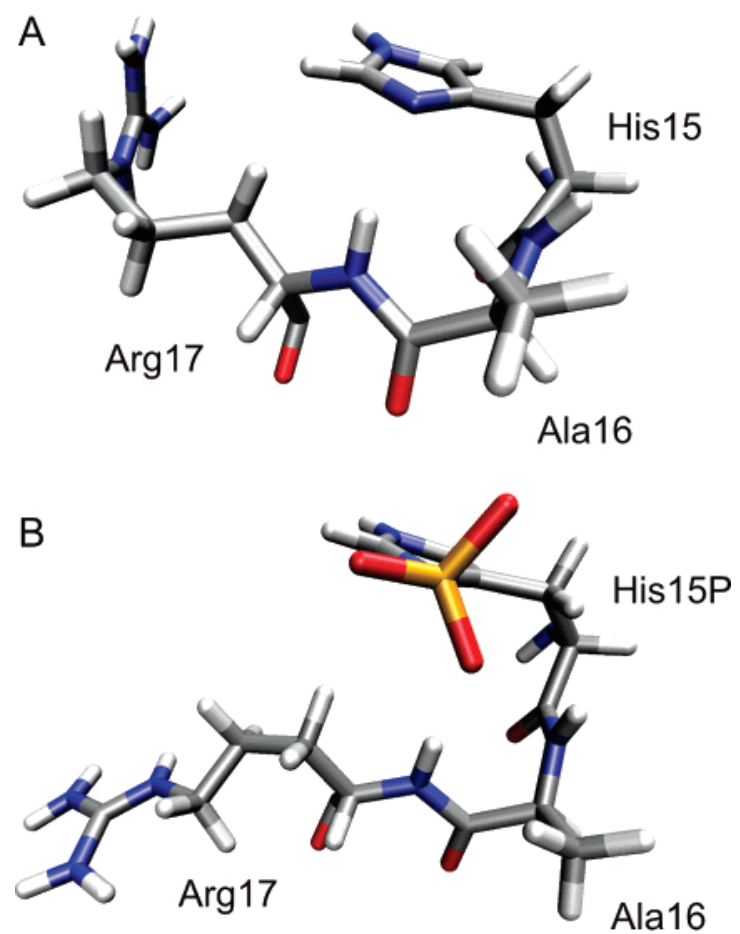

FIGURE 8: CLOSED active site conformation in the presence and absence of phosphate at His15. Active sites of the structures recorded after 2 ns of MD of $1 \mathrm{JEM} \mathrm{HPr}-\mathrm{His} 15_{\mathrm{H} \epsilon}$ (A) and after 7 ns of MD of 1JEM HPr-His15P (B) are displayed in detail. Atoms are colored according to the CPK color code.

Table 3: Protonation of the Imidazole of His15P in Seven Models of the 1JEM Ensemble and Four Snapshots from the MD Simulation $^{a}$

\begin{tabular}{lccccccc}
\hline \multicolumn{1}{c}{ model } & $\Delta G_{\text {Born }}$ & $\Delta G_{\text {back }}$ & $\left\langle\Delta \bar{G}_{\text {inter }}\right\rangle$ & $\Delta G_{\text {model }}{ }^{b}$ & sum & $\mathrm{p} K_{\text {app }}$ & $d_{1}$ \\
\hline 1 & -2.6 & 1.9 & 0.9 & -9.6 & -9.4 & 6.9 & 3.57 \\
2 & -2.1 & 1.9 & 1.8 & -9.6 & -8.0 & 5.8 & 3.60 \\
3 & -2.2 & 1.8 & 0.9 & -9.6 & -9.1 & 6.6 & 2.21 \\
13 & -2.2 & 1.3 & 0.4 & -9.6 & -10.1 & 7.3 & 2.21 \\
14 & -2.1 & 1.4 & 1.2 & -9.6 & -9.1 & 6.6 & 2.20 \\
16 & -2.2 & 1.4 & 1.0 & -9.6 & -9.5 & 6.9 & 2.92 \\
22 & -2.0 & 1.8 & 0.9 & -9.6 & -8.9 & 6.5 & 2.20 \\
MD (5200 ps) & -3.3 & 1.8 & -0.5 & -9.6 & -11.7 & 8.5 & 1.91 \\
MD (5934 ps) & -2.6 & 1.7 & -0.5 & -9.6 & -11.1 & 8.1 & 1.88 \\
MD (8300 ps) & -3.3 & 2.4 & -0.5 & -9.6 & -11.1 & 7.9 & 4.5 \\
MD (8600 ps) & -2.4 & 1.5 & -0.5 & -9.6 & -11.0 & 7.9 & 4.6 \\
\hline
\end{tabular}

${ }^{a}$ Energy decomposition of apparent $\mathrm{p} K_{\mathrm{a}}$ values into Born $\left(\Delta G_{\mathrm{Born}}\right)$, background $\left(\Delta G_{\text {back }}\right)$, model $\left(\Delta G_{\text {model }}\right)$, and mean-field interaction energy $\left(\left\langle\Delta \bar{G}_{\text {inter }}\right\rangle\right)$ differences of His15P in kilocalories per mole. The mean-field interaction energy is calculated using probabilities at the $\mathrm{pH}$ equal to the apparent $\mathrm{p} K_{\mathrm{a}}$ value. The shortest distance $\left(d_{1}\right)$ between a phosphate group oxygen and the Arg17 amide hydrogen for each structure is listed in angstroms. ${ }^{b} \Delta G_{\text {model }}=-R T \ln 10 \mathrm{p} K_{\mathrm{a} \text {, model }}$ with $\mathrm{p} K_{\mathrm{a} \text {, model }}$ values of 7.0 and 6.6 for $\mathrm{N} \epsilon 2$ and $\mathrm{N} \delta 1$, respectively.

To substantiate this point and to identify those interactions that stabilize the CLOSED HPr-His15P conformation, we performed a $9 \mathrm{~ns}$ MD simulation. The simulation reveals only minor structural fluctuations, and the CLOSED conformation remains stable over the entire simulation time. To discriminate whether the histidine ring itself or the attached phosphate group predominantly accounts for the maintenance of the CLOSED conformation, the average interaction energies of both groups with the remaining residues of $\mathrm{HPr}$ were calculated separately (Figure 9).

The phosphate group (Figure 9, light gray) forms highly favorable interactions with residues Ala16 $(-9.3 \mathrm{kcal} / \mathrm{mol})$ and $\operatorname{Arg} 17$ ( $-5.3 \mathrm{kcal} / \mathrm{mol})$ and, to a lesser extent, unfavorable interactions with residues Asp11 (4.9 kcal/mol) and Ile14 $(2.1 \mathrm{kcal} / \mathrm{mol})$. The latter can be attributed to the electrostatic repulsion between the negatively charged phosphate group and some partially negatively charged atoms such as, for example, oxygen atoms, but the net interaction energy of the phosphate group remains negative $(-10.4 \mathrm{kcal} /$ mol) in the CLOSED conformation.

For the $\mathrm{His}^{+}$ring (Figure 9, dark gray), a repulsive interaction is observed with $\operatorname{Arg} 17$, which is similar to the effect observed for the positively charged ring in the CLOSED conformation of unphosphorylated HPr (Figure 7A). The considerably unfavorable interaction of the His ${ }^{+}$ ring with $\operatorname{Arg} 17(2.2 \mathrm{kcal} / \mathrm{mol})$ is counterbalanced by favorable interactions of His ${ }^{+}$with Asp11 ( $\left.-1.5 \mathrm{kcal} / \mathrm{mol}\right)$ and Glu84 $(-1.5 \mathrm{kcal} / \mathrm{mol})$, but the major contribution to the stabilization of the CLOSED conformation comes from the overall highly favorable interaction of the phosphate group $(-10.4 \mathrm{kcal} / \mathrm{mol})$.

A more detailed analysis revealed that the phosphoryl group oxygen atoms form a backbone hydrogen bond with either Ala16 or Arg17 in more than $70 \%$ of the structures collected during MD simulation. The results of our simulation also suggest that the two possible $\mathrm{H}$-bonds between the amide hydrogen atoms and the phosphoryl group are usually not formed simultaneously. These backbone hydrogen bonds have been postulated previously on the basis of NMR spectroscopic data $(10,15)$, but detailed inspection of the hydrogen bonding pattern was hampered by the lack of NOE distance restraints from the phosphate group. As a consequence, the hydrogen bond between the phosphate group oxygens and the Arg17 backbone hydrogen, despite being discussed in the literature, is quite long in the models taken from the set of NMR structures (see Table 3).

Therefore, we investigated whether the $\mathrm{p} K_{\mathrm{a}}$ values obtained for the structures refined by MD simulation are in agreement with the experimental $\mathrm{p} K_{\mathrm{a}}$ value and whether a tighter hydrogen bond formed by the phosphate group and the HPr backbone during simulation has a key effect on the $\mathrm{p} K_{\mathrm{a}}$ value. For the analysis, four structures (two with and two without a hydrogen bond) were selected from the MD simulation. Their apparent $\mathrm{p} K_{\mathrm{a}}$ values, which are in the range from 7.9 to 8.5 (Table 3), are in good agreement with the reported experimental values between 7.7 and $8.3(5,39)$. This finding shows that the MD simulations have actually led to a structural refinement and that the tighter hydrogen bond has only a marginal effect on the $\mathrm{p} K_{\mathrm{a}}$ value.

The energy decomposition shows that the source of the difference in the apparent $\mathrm{p} K_{\mathrm{a}}$ value is not only the meanfield interaction energy, as the background energy and Born energy also change considerably. The mean-field interaction energy close to zero indicates that titrating residues do not play a major role in determining the protonation state of His15P. Thus, small structural changes, which have occurred during the MD simulation, lead to lower sums of Born and background energy and are therefore independent of the presence of the hydrogen bond.

Despite a thorough analysis, we were not able to detect one particular conformational change compared to the starting structure that accounts for the shift in the $\mathrm{p} K_{\mathrm{a}}$ values. This finding underlines the fact that the MD simulation did not result in any larger structural changes but only in a 


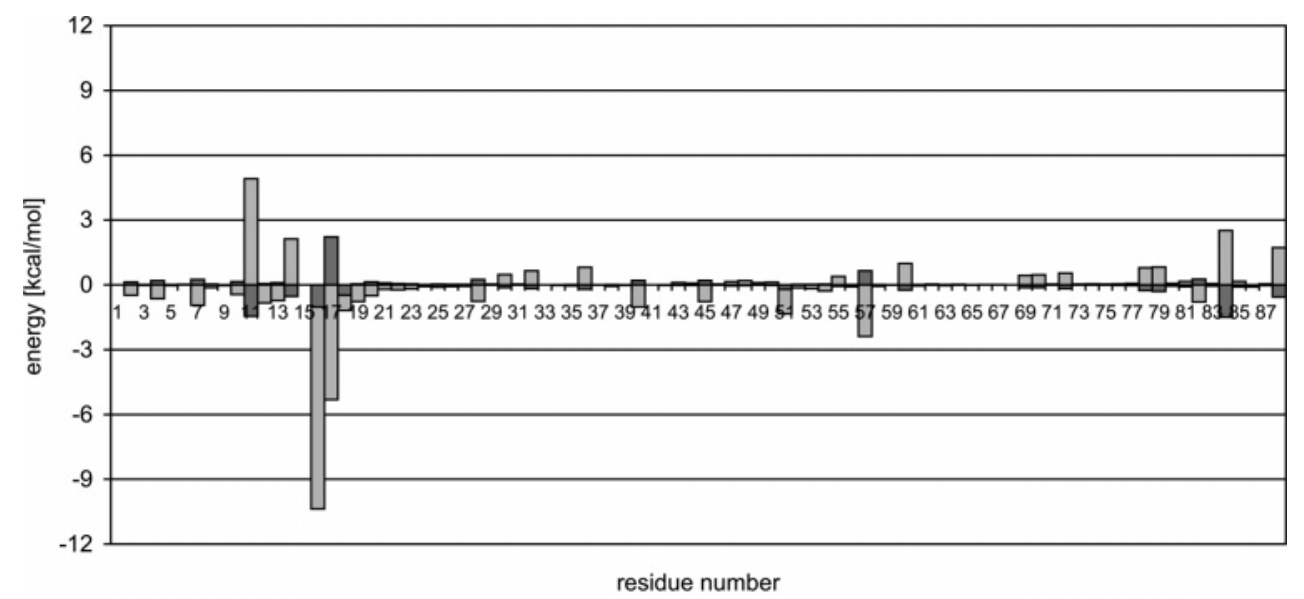

FIGURE 9: Decomposition of the interaction energies between different parts of the His15 side chain and all other amino acids of HPrHis15P. Interaction energies of the imidazole ring atoms (dark gray) and the phosphate group atoms (light gray) are plotted vs the sequence number of the interacting residues. The bars are shown as stacked plots. Energy values were averaged using the snapshots recorded during the $2-3$ ns time interval of the HPr-His15P simulation.

refinement of the local vicinity of His $15 \mathrm{P}$ compared to the starting structure. Additionally, this result emphasizes that the accuracy of three-dimensional structures is important for the calculation of $\mathrm{p} K_{\mathrm{a}}$ values.

In summary, it was possible to improve the structure of HPr-His15P by MD simulation, leading to almost perfect agreement between theory and experiment for the $\mathrm{p} K_{\mathrm{a}}$ values of His $15 \mathrm{P}$, and to identify those interactions that stabilize the CLOSED conformation even in the presence of a positively charged imidazole ring.

Application of the Four-Microstate Model to HPr-His15P. Finally, we tested whether the conformational properties of HPr-His 15P can be predicted correctly by the four-microstate model using the following input data. The $\mathrm{p} K_{\mathrm{a}}$ value of the CLOSED conformation was taken from our calculations on the MD-refined CLOSED structures $\left(\mathrm{p} K_{\mathrm{app}, 1}=8.0\right)$, which agree well with literature values (5). In a hypothetical OPEN conformation, the imidazole ring will show no major interactions with the rest of the protein, and therefore, $\mathrm{p} K_{\mathrm{app}, 2}$ is approximated by the model $\mathrm{p} K_{\mathrm{a}}$ value for phosphohistidine in aqueous solution ( $\left.\mathrm{p} K_{\mathrm{app}, 2}=7.0\right)$. It can also be assumed that the conformational energy $\Delta G_{\text {conf }}$ of HPr-His15P is in the same range as that for HPr-His 15 since this energy term is primarily the torsional energy difference around $\chi_{1}$ and $\chi_{2}$ of the histidine side chain, and other conformational strain differences in the protein, which should not be strongly affected by the phosphorylation.

The microstates were defined and analyzed in an identical fashion as described above for the unphosphorylated HPr. The resulting probability plots show that for HPr-His15P the CLOSED conformation is predominantly populated for both protonation forms of the histidine ring (Figure 4G,H). This finding is consistent with experiment and with our MD simulation showing that, in contrast to unphosphorylated HPr, the protonation of the ring does not induce an OPEN conformation in HPr-His15P.

It is remarkable that the same four-microstate model can explain both the $\mathrm{pH}$-dependent conformational changes of HPr-His 15 and the conformational rigidity of HPr-His15P. In case of HPr-His15, the model also achieves agreement between the theoretical and the experimental titration studies, since the conformational variability is considered. In the case of HPr-His15P, agreement between theoretical and experimental $\mathrm{p} K_{\mathrm{a}}$ values is achieved by using MD-refined structures.

By using only apparent $\mathrm{p} K_{\mathrm{a}}$ values from detailed structurebased calculations, the mesoscopic picture of the fourmicrostate model elegantly overcomes problems arising from irrelevant structural differences, e.g., between HPr's from various bacterial species. As shown in this study (Table 2), the apparent $\mathrm{p} K_{\mathrm{a}}$ values of different structures agree well, so it is reasonable to assume that they can be transferred between different structures and it is not necessary to include all structural detail. Thus, this microstate model provides a fast and robust method for predicting the effect of protonation on the conformational stability of proteins.

Biological Implications. We examined whether a functional role of the different active site geometries and the conformational flexibility detected for HPr exists. For that purpose, the structures of phosphorylated and unphosphorylated HPr in complex with different interaction partners were analyzed.

HPr is phosphorylated at His 15 by enzyme I (EI), and the structure of the respective complex (Figure S3 of the Supporting Information) (45) indicates that the CLOSED form of free HPr, which was shown to be the primarily populated conformation at pH 7 (Figure 4), is appropriate for complex formation. Additionally, the very low apparent $\mathrm{p} K_{\mathrm{a}}$ of the CLOSED conformation ensures that free HPr is only singly protonated, and the protonation probability of His15 indicates that the single proton present at the imidazole ring is predominantly bound to the $\mathrm{N} \epsilon 2$ atom (Figure 2). Thus, free HPr is not only stabilized in a conformation competent for binding to EI but also primed to accept the phosphate group at $\mathrm{N} \delta 1$.

Attachment of the phosphate group changes the electrostatic properties of the imidazole ring, and the $\mathrm{N} \epsilon 2$-protonated form now bears a positive charge. The favorable intramolecular interactions formed by the phosphate group, however, ensure that HPr-His15P remains in the CLOSED conformation and does not undergo structural transition. This CLOSED conformation is also retained in the complexes of HPr with various structurally different Enzyme IIA proteins (46-48) (e.g., Figure S3), showing that the transfer of the phosphate 
from EI to HPr and further onto EIIA can be accomplished without a larger structural rearrangement of His15P.

While the OPEN conformation does thus not seem to play a role in phosphate transfer within the PTS, it is important for the regulatory function of HPr which is accomplished by binding to the transcriptional regulator CcpA. In this complex $(49,50)$, His 15 adopts an OPEN conformation, which is stabilized by a hydrogen bond to the side chain of Asp296 of CcpA (Figure S3).

Therefore, the conformational flexibility of His15 in unphosphorylated HPr may be required because of its dual role as both a phosphotransfer protein in the PTS and an allosteric effector in transcriptional regulation. The existence of an equilibrium between the CLOSED and OPEN form might be essential for fulfilling this dual function. In contrast, HPr phosphorylated at His15, which no longer binds to the transcriptional regulator $\mathrm{CcpA}$, adopts only a single rigid active site conformation.

\section{ACKNOWLEDGMENT}

We thank the Regionales Rechenzentrum Erlangen for computational resources and D. Bashford for providing his program MEAD.

\section{SUPPORTING INFORMATION AVAILABLE}

A figure visualizing the mean-field interaction energy differences for the protonation reaction at $\mathrm{N} \delta 1$ and at $\mathrm{N} \epsilon 2$ with other titratable groups (Figure S1), the His15-Arg17 interaction energies (Figure S2), and the conformation of His 15 and Arg17 in three HPr-containing complexes (Figure S3). This material is available free of charge via the Internet at http://pubs.acs.org.

\section{REFERENCES}

1. Kundig, W., Ghosh, S., and Roseman, S. (1964) Phosphate Bound to Histidine in a Protein as an Intermediate in a Novel PhosphoTransferase System, Proc. Natl. Acad. Sci. U.S.A. 52, 1067-1074.

2. Titgemeyer, F., and Hillen, W. (2002) Global control of sugar metabolism: A Gram-positive solution, Antonie Van Leeuwenhoek $82,59-71$

3. Deutscher, J., and Saier, M. H., Jr. (1983) ATP-dependent protein kinase-catalyzed phosphorylation of a seryl residue in HPr, a phosphate carrier protein of the phosphotransferase system in Streptococcus pyogenes, Proc. Natl. Acad. Sci. U.S.A. 80, 67906794.

4. Vadeboncoeur, C. (1995) HPr: Heteromorphous protein, Res. Microbiol. 146, 525-530.

5. Waygood, E. B. (1998) The structure and function of HPr, Biochem. Cell Biol. 76, 359-367.

6. Stulke, J., and Hillen, W. (1998) Coupling physiology and gene regulation in bacteria: The phosphotransferase sugar uptake system delivers the signals, Naturwissenschaften 85, 583-592.

7. Kotrba, P., Inui, M., and Yukawa, H. (2001) Bacterial phosphotransferase system (PTS) in carbohydrate uptake and control of carbon metabolism, J. Biosci. Bioeng. 92, 502-517.

8. Stulke, J., Arnaud, M., Rapoport, G., and Martin-Verstraete, I. (1998) PRD: A protein domain involved in PTS-dependent induction and carbon catabolite repression of catabolic operons in bacteria, Mol. Microbiol. 28, 865-874.

9. van Nuland, N. A., Hangyi, I. W., van Schaik, R. C., Berendsen, H. J., van Gunsteren, W. F., Scheek, R. M., and Robillard, G. T. (1994) The high-resolution structure of the histidine-containing phosphocarrier protein HPr from Escherichia coli determined by restrained molecular dynamics from nuclear magnetic resonance nuclear Overhauser effect data, J. Mol. Biol. 237, 544-559.

10. van Nuland, N. A., Boelens, R., Scheek, R. M., and Robillard, G. T. (1995) High-resolution structure of the phosphorylated form of the histidine-containing phosphocarrier protein HPr from
Escherichia coli determined by restrained molecular dynamics from NMR-NOE data, J. Mol. Biol. 246, 180-193.

11. Jia, Z., Vandonselaar, M., Hengstenberg, W., Quail, J. W., and Delbaere, L. T. (1994) The 1.6 A structure of histidine-containing phosphotransfer protein HPr from Streptococcus faecalis, J. Mol. Biol. 236, 1341-1355.

12. Audette, G. F., Engelmann, R., Hengstenberg, W., Deutscher, J., Hayakawa, K., Quail, J. W., and Delbaere, L. T. (2000) The 1.9 $\AA$ resolution structure of phospho-serine 46 HPr from Enterococcus faecalis, J. Mol. Biol. 303, 545-553.

13. Maurer, T., Doker, R., Gorler, A., Hengstenberg, W., and Kalbitzer, H. R. (2001) Three-dimensional structure of the histidinecontaining phosphocarrier protein (HPr) from Enterococcus faecalis in solution, Eur. J. Biochem. 268, 635-644.

14. Herzberg, O., Reddy, P., Sutrina, S., Saier, M. H., Jr., Reizer, J., and Kapadia, G. (1992) Structure of the histidine-containing phosphocarrier protein $\mathrm{HPr}$ from Bacillus subtilis at 2.0-A resolution, Proc. Natl. Acad. Sci. U.S.A. 89, 2499-2503.

15. Jones, B. E., Rajagopal, P., and Klevit, R. E. (1997) Phosphorylation on histidine is accompanied by localized structural changes in the phosphocarrier protein, $\mathrm{HPr}$ from Bacillus subtilis, Protein Sci. 6, 2107-2119.

16. Kalbitzer, H. R., Gorler, A., Li, H., Dubovskii, P. V., Hengstenberg, W., Kowolik, C., Yamada, H., and Akasaka, K. (2000) ${ }^{15} \mathrm{~N}$ and ${ }^{1} \mathrm{H}$ NMR study of histidine containing protein (HPr) from Staphylococcus carnosus at high pressure, Protein Sci. 9, 693703.

17. Moglich, A., Koch, B., Gronwald, W., Hengstenberg, W., Brunner, E., and Kalbitzer, H. R. (2004) Solution structure of the activecentre mutant I14A of the histidine-containing phosphocarrier protein from Staphylococcus carnosus, Eur. J. Biochem. 271, 4815-4824.

18. Maurer, T., Meier, S., Kachel, N., Munte, C. E., Hasenbein, S., Koch, B., Hengstenberg, W., and Kalbitzer, H. R. (2004) Highresolution structure of the histidine-containing phosphocarrier protein (HPr) from Staphylococcus aureus and characterization of its interaction with the bifunctional HPr kinase/phosphorylase, J. Bacteriol. 186, 5906-5918.

19. Kalbitzer, H. R., and Hengstenberg, W. (1993) The solution structure of the histidine-containing protein (HPr) from Staphylococcus aureus as determined by two-dimensional ${ }^{1} \mathrm{H}-\mathrm{NMR}$ spectroscopy, Eur. J. Biochem. 216, 205-214.

20. Kruse, R., Hengstenberg, W., Beneicke, W., and Kalbitzer, H. R. (1993) Involvement of various amino- and carboxyl-terminal residues in the active site of the histidine-containing protein $\mathrm{HPr}$ of the phosphoenolpyruvate-dependent phosphotransferase system of Staphylococcus carnosus: Site-directed mutagenesis with the ptsH gene, biochemical characterization and NMR studies of the mutant proteins, Protein Eng. 6, 417-423.

21. Jia, Z., Vandonselaar, M., Quail, J. W., and Delbaere, L. T. (1993) Active-centre torsion-angle strain revealed in $1.6 \AA$-resolution structure of histidine-containing phosphocarrier protein, Nature 361, 94-97.

22. Ullmann, G. M., and Knapp, E. W. (1999) Electrostatic models for computing protonation and redox equilibria in proteins, Eur. Biophys. J. 28, 533-551.

23. Fieulaine, S., Morera, S., Poncet, S., Mijakovic, I., Galinier, A., Janin, J., Deutscher, J., and Nessler, S. (2002) X-ray structure of a bifunctional protein kinase in complex with its protein substrate HPr, Proc. Natl. Acad. Sci. U.S.A. 99, 13437-13441.

24. Homeyer, N., Horn, A. H. C., Lanig, H., and Sticht, H. (2006) AMBER force-field parameters for phosphorylated amino acids in different protonation states: Phosphoserine, phosphothreonine, phosphotyrosine, and phosphohistidine, J. Mol. Model. 12, 281289.

25. Gassner, M., Stehlik, D., Schrecker, O., Hengstenberg, W., Maurer, W., and Ruterjans, H. (1977) The phosphoenolpyruvate-dependent phosphotransferase system of Staphylococcus aureus. $2 .{ }^{1} \mathrm{H}$ and ${ }^{31} \mathrm{P}$-nuclear-magnetic-resonance studies on the phosphocarrier protein HPr, phosphohistidines and phosphorylated HPr, Eur. J. Biochem. 75, 287-296.

26. Bashford, D., and Gerwert, K. (1992) Electrostatic calculations of the $\mathrm{pKa}$ values of ionizable groups in bacteriorhodopsin, $J$. Mol. Biol. 224, 473-486.

27. Bashford, D. (1997) An Object-Oriented Programming Suite for Electrostatic Effects in Biological Molecules, in Proceedings of Scientific Computing in Object-Oriented Parallel Environments, ISCOPE97, Marina del Rey, CA, December 8-11, 1997 (Ish- 
ikawa, Y., Oldehoeft, R. R., Reynders, J. V. W., and Tholburn, M., Eds.) pp 233-240, Springer, Berlin.

28. Tanford, C., and Roxby, R. (1972) Interpretation of protein titration curves. Application to lysozyme, Biochemistry 11, 2192-2198.

29. Sayle, R. A., and Milner-White, E. J. (1995) RASMOL: Biomolecular graphics for all, Trends Biochem. Sci. 20, 374.

30. Case, D. A., Pearlman, D. A., Caldwell, J. W., III, Cheatham, T., Wang, J., Ross, W. S., Simmerling, C. L., Darden, T. A., Merz, K. M., Stanton, R. V., Cheng, A. L., Vincent, J. J., Crowley, M., Tsui, V., Gohlke, H., Radmer, R. J., Duan, Y., Pitera, J., Massova, I., Seibel, G. L., Singh, U. C., Weiner, P. K., and Kollman, P. A. (2002) AMBER7.0, University of California, San Francisco.

31. Jorgensen, W. L., Chandrasekhar, J., Madura, J. D., Impey, R. W., and Klein, M. L. (1983) Comparison of simple potential functions for simulating liquid water, J. Chem. Phys. 79, 926935.

32. Cornell, W. D., Cieplak, P., Bayly, C. I., Gould, I. R., Merz, K. M., Jr., Ferguson, D. M., Spellmeyer, D. C., Fox, T., Caldwell, J. W., and Kollman, P. A. (1995) A Second Generation Force Field for the Simulaton of Proteins, Nucleic Acids and Organic Molecules, J. Am. Chem. Soc. 117, 5179-5197.

33. Cheatham, T. E., III, Cieplak, P., and Kollman, P. A. (1999) A modified version of the Cornell et al. force field with improved sugar pucker phases and helical repeat, J. Biomol. Struct. Dyn. $16,845-862$.

34. Homeyer, N., Essigke, T., Meiselbach, H., Ullmann, G. M., and Sticht, H. (2006) Effect of HPr phosphorylation on structure, dynamics, and interactions in the course of transcriptional control, J. Mol. Model. 13, 431-444.

35. Humphrey, W., Dalke, A., and Schulten, K. (1996) VMD: Visual molecular dynamics, J. Mol. Graphics 14, 33-38.

36. Brünger, A. T. (1992) X-PLOR, Yale University Press, New Haven, CT.

37. Tripos (1991-2002) SYBYL, St. Louis, MO.

38. Hahmann, M., Maurer, T., Lorenz, M., Hengstenberg, W., Glaser, S., and Kalbitzer, H. R. (1998) Structural studies of histidinecontaining phosphocarrier protein from Enterococcus faecalis, Eur. J. Biochem. 252, 51-58.

39. Rajagopal, P., Waygood, E. B., and Klevit, R. E. (1994) Structural consequences of histidine phosphorylation: NMR characterization of the phosphohistidine form of histidine-containing protein from Bacillus subtilis and Escherichia coli, Biochemistry 33, 1527115282.

40. Kalbitzer, H. R., Hengstenberg, W., Rosch, P., Muss, P., Bernsmann, P., Engelmann, R., Dorschug, M., and Deutscher, J. (1982) HPr proteins of different microorganisms studied by hydrogen-1 high-resolution nuclear magnetic resonance: Similarities of structures and mechanisms, Biochemistry 21, 2879-2885.

41. Anderson, J. W., Pullen, K., Georges, F., Klevit, R. E., and Waygood, E. B. (1993) The involvement of the arginine 17 residue in the active site of the histidine-containing protein, HPr, of the phosphoenolpyruvate:sugar phosphotransferase system of Escherichia coli, J. Biol. Chem. 268, 12325-12333.

42. Richarz, R., and Wüthrich, K. (1978) Carbon-13 NMR Chemical Shifts of the Common Amino Acid Residues Measured in Aqueous Solutions of the Linear Tetrapeptides H-Gly-Gly-X-LAla-OH, Biopolymers 17, 2133-2141.

43. Ullmann, G. M. (2003) Relations between Protonation Constants and Titration Curves in Polyprotic Acids: A Critical View, $J$. Phys. Chem. B 107, 1263-1271.

44. Klingen, A. R., Bombarda, E., and Ullmann, G. M. (2006) Theoretical investigation of the behavior of titratable groups in proteins, Photochem. Photobiol. Sci. 5, 588-596.

45. Garrett, D. S., Seok, Y. J., Peterkofsky, A., Gronenborn, A. M., and Clore, G. M. (1999) Solution structure of the 40,000 Mr phosphoryl transfer complex between the N-terminal domain of enzyme I and HPr, Nat. Struct. Biol. 6, 166-173.

46. Cornilescu, G., Lee, B. R., Cornilescu, C. C., Wang, G., Peterkofsky, A., and Clore, G. M. (2002) Solution structure of the phosphoryl transfer complex between the cytoplasmic A domain of the mannitol transporter IIMannitol and HPr of the Escherichia coli phosphotransferase system, J. Biol. Chem. 277, 42289-42298.

47. Wang, G., Louis, J. M., Sondej, M., Seok, Y. J., Peterkofsky, A., and Clore, G. M. (2000) Solution structure of the phosphoryl transfer complex between the signal transducing proteins HPr and IIA(glucose) of the Escherichia coli phosphoenolpyruvate:sugar phosphotransferase system, EMBO J. 19, 5635-5649.

48. Williams, D. C., Jr., Cai, M., Suh, J. Y., Peterkofsky, A., and Clore, G. M. (2005) Solution NMR structure of the $48-\mathrm{kDa}$ IIAMannose-HPr complex of the Escherichia coli mannose phosphotransferase system, J. Biol. Chem. 280, 20775-20784.

49. Schumacher, M. A., Allen, G. S., Diel, M., Seidel, G., Hillen, W., and Brennan, R. G. (2004) Structural basis for allosteric control of the transcription regulator CcpA by the phosphoprotein HPr-Ser46-P, Cell 118, 731-741.

50. Schumacher, M. A., Seidel, G., Hillen, W., and Brennan, R. G. (2007) Structural Mechanism for the Fine-tuning of CcpA Function by The Small Molecule Effectors Glucose 6-Phosphate and Fructose 1,6-Bisphosphate, J. Mol. Biol. 368, 1042-1050.

BI701228G 